\title{
Estimating Particulate Matter using satellite based aerosol optical depth and meteorological variables in Malaysia
}

\author{
Nurul Amalin Fatihah Kamarul Zaman ${ }^{\mathrm{a}}$, Kasturi Devi Kanniah ${ }^{\mathrm{a}, \mathrm{c}, *}$, Dimitris G. Kaskaoutis ${ }^{\mathrm{b}}$ \\ a Tropical Map Research Group, Faculty of Geoinformation and Real Estate, Universiti Teknologi Malaysia, 81310 Skudai, Johor Darul Takzim, Malaysia \\ b Atmospheric Research Team, Institute for Environmental Research and Sustainable Development, National Observatory of Athens, GR-11810 Athens, Greece \\ ${ }^{c}$ Centre for Environmental Sustainability and Water Security (IPASA), Research Institute for Sustainable Environment (RISE), Universiti Teknologi Malaysia, 81310 UTM \\ Johor Bahru, Johor
}

\section{A R T I C L E I N F O}

\section{Keywords:}

$\mathrm{PM}_{10}$

Satellite remote sensing

Artificial Neural Network

Multiple linear regressions

Meteorology

Malaysia

\begin{abstract}
A B S T R A C T
The insufficient number of ground-based stations for measuring Particulate Matter $<10 \mu \mathrm{m}\left(\mathrm{PM}_{10}\right)$ in the developing countries hinders $\mathrm{PM}_{10}$ monitoring at a regional scale. The present study aims to develop empirical models for $\mathrm{PM}_{10}$ estimation from space over Malaysia using aerosol optical depth $\left(\mathrm{AOD}_{550}\right)$ and meteorological (surface temperature, relative humidity and atmospheric stability) data (retrieved or estimated) from Moderate Resolution Imaging Spectroradiometer (MODIS) during the period 2007-2011. The MODIS retrievals are found to be satisfactorily correlated with ground-based measurements at Malaysia. Multiple linear regressions (MLR) and Artificial Neural Network (ANN) techniques are utilized to develop the empirical models for $\mathrm{PM}_{10}$ estimation. The model development and training are performed via comparison with measured $\mathrm{PM}_{10}$ at 29 stations over Malaysia and reveal that the ANN provides slightly higher accuracy with $R^{2}=0.71$ and RMSE $=11.61 \mu \mathrm{g} \mathrm{m}^{-3}$ compared to the MLR method $\left(\mathrm{R}^{2}=0.66\right.$ and RMSE $\left.=12.39 \mu \mathrm{g} \mathrm{m}^{-3}\right)$. Stepwise regression analysis performed on the MLR method reveals that the MODIS AOD $_{550}$ is the most important parameter for $\mathrm{PM}_{10}$ estimations $\left(\mathrm{R}^{2}=0.59\right.$ and $\left.\mathrm{RMSE}=13.61 \mu \mathrm{g} \mathrm{m}^{-3}\right)$; however, the inclusion of the meteorological parameters in the MLR increases the accuracy of the retrievals $\left(R^{2}=0.66\right.$, RMSE $=12.39 \mu \mathrm{g} \mathrm{m}^{-3}$ ). The estimated $\mathrm{PM}_{10}$ concentrations are finally validated against surface measurements at 16 stations resulting in similar performance from the ANN model $\left(R^{2}=0.58, R M S E=10.16 \mu \mathrm{g} \mathrm{m}^{-3}\right)$ and MLR technique $\left(\mathrm{R}^{2}=0.56\right.$, RMSE $\left.=10.58 \mu \mathrm{g} \mathrm{m}^{-3}\right)$. The significant accuracy that has been attained in $\mathrm{PM}_{10}$ estimations from space allows us to assess the pollution levels in Malaysia and map the $\mathrm{PM}_{10}$ distribution at large spatial and temporal scales.
\end{abstract}

\section{Introduction}

Air pollution has become a serious environmental problem in the developing southeast Asian countries, especially in Malaysia that is aiming to become an industrial nation by 2020 . Malaysia is ranked as the 117th worst country among 180 nations worldwide in terms of air quality (EPI, 2016) with the major sources of air pollutants to be open biomass burning, motor vehicles and industries (Afroz et al., 2003; Hyer et al., 2013; Alias et al., 2014; Khan et al., 2016a). Besides the local sources, biomass-burning aerosols from wildfires in Indonesia are also transported over Malaysia particularly during the dry season and southwest monsoon (Kanniah et al., 2014a; Khan et al., 2016b). Furthermore, Malaysia lies in the main pathway of the southeast Asian pollution outflow (Lawrence and Lelieveld, 2010; Reid et al., 2013; Wang et al., 2013), which contributes significantly to the local aerosol and pollutant emissions. The air pollution levels in Malaysia are expressed via the Air Pollution Index (API) that is calculated using surface concentrations of carbon monoxide (CO), tropospheric ozone $\left(\mathrm{O}_{3}\right)$, nitrogen dioxide $\left(\mathrm{NO}_{2}\right)$, sulphur dioxide $\left(\mathrm{SO}_{2}\right)$ and Particulate Matter $<10 \mu \mathrm{m}\left(\mathrm{PM}_{10}\right.$ ) (Awang et al., 2000; Dominick et al., 2012).

$\mathrm{PM}_{10}$ is an important component of air-pollution monitoring networks since it affects human health by causing respiratory problems (Balakrishnan et al., 2002; Pope et al., 2011a, b; Ha Trang and Tripathi, 2014), while inhaling $\mathrm{PM}_{10}$, and most particularly Particulate Matter < $2.5 \mu \mathrm{m}\left(\mathrm{PM}_{2.5}\right)$, can cause cardiovascular diseases (Dominici et al., 2006), birth defects and premature death (Ballester et al., 2010). $\mathrm{PM}_{10}$, as aerosol particles, can also affect the climate system by scattering and absorbing the incoming solar radiation resulting in heating and/or cooling effects (Ramanathan and Carmichael, 2008) depending on the type of particles (i.e. dust, soot or anthropogenic pollution), optical and

\footnotetext{
* Corresponding author.

E-mail address: kasturi@utm.my (K.D. Kanniah).
} 
chemical properties.

Satellite remote sensing has been increasingly available for $\mathrm{PM}_{10}$ monitoring studies over a large spatial domain. Remote-sensing retrievals of aerosol optical depth (AOD) from multiple satellite sensors, such as Multiangle Imaging Spectroradiometer (MISR) (Liu et al., 2007; Van Donkelaar. et al., 2010; Dey et al., 2012; Sotoudeheian and Arhami, 2014), Spinning Enhanced Visible and Infrared Imager (SEVIRI) (Emili et al., 2010), Moderate Resolution Imaging Spectroradiometer (MODIS) (Gupta et al., 2006; Van Donkelaar. et al., 2010; Jamil et al., 2011; Nordio et al., 2013; Yap and Hashim, 2013; Chitranshi et al., 2014), Medium Resolution Imaging Spectrometer (MERIS) (Kaskaoutis et al., 2010; Kanniah et al., 2014b; Beloconi et al., 2016) and Landsat (Nguyen and Tran, 2014; Nadzri et al., 2010) are commonly used to estimate $\mathrm{PM}_{10}$ and/or $\mathrm{PM}_{2.5}$ from space.

Among the available remote-sensing data, MODIS AOD is found to have high retrieval accuracy over land (i.e. $\pm 0.05 *$ AOD under clear skies and $\pm 0.15 *$ AOD under moderately cloud-contaminated atmospheres), as well as nearly daily global coverage (Remer et al., 2008). Validation of MODIS AOD retrieved from both Terra and Aqua satellites showed high correlation $\left(\mathrm{R}^{2}=0.9\right)$ with AERONET AODs worldwide (Levy et al., 2010) and, over Malaysia $\left(\mathrm{R}^{2}=0.55\right)$ in particular (Kanniah et al., 2014a). Nevertheless, a main drawback for usage of MODIS AOD is its coarse spatial resolution $(10 \mathrm{~km})$ that may tend to generalize AOD information spatially. Therefore, especially over urban environments that are characterized by heterogeneous surfaces, satellite AOD of higher spatial resolution is preferred for $\mathrm{PM}_{10}$ estimations. In this respect, MERIS AOD and synergized MERIS/AATSR data (North et al., 2009) have been recently used although MERIS's relatively poor performance compared to MODIS (Kaskaoutis et al., 2010; Benas et al., 2013; Kanniah et al., 2014b). Furthermore, MODIS-AOD retrievals at 3$\mathrm{km}$ spatial resolution are also considered as not so suitable for airquality studies due to improper characterization of the underlying urban surfaces that resulted in significant bias for AODs $>0.1$ (Levy et al., 2013; Munchak et al., 2014; Xie et al., 2015).

Several studies have used only the satellite AOD via simple linear regressions for PM estimations from space resulting in correlation coefficients around 0.52 to 0.77 between measured and estimated $\mathrm{PM}_{10}$ concentrations (Gupta and Christopher, 2008; Schaap et al., 2009; Kanniah et al., 2016). According to Gupta and Christopher (2009a, b), AOD alone is not a good predictor of PM, since AOD corresponds to the total columnar aerosol, whereas PM refers to particle concentration at the surface; therefore, the correlation between PM and AOD strongly depends on the vertical distribution of aerosols and several meteorological factors, i.e., profiles of potential temperature and wind regime (Chitranshi et al., 2014; Sinha et al., 2015). On the other hand, the satellite snap-shots usually cover large spatial areas and are subject to cloud contamination (Zhang et al., 2005; Gupta et al., 2006). Therefore, incorporation of other meteorological parameters, such as ambient relative humidity $(\mathrm{RH})$, fractional cloud cover and mixing layer height, improved the prediction of PM, since weather conditions can greatly affect the aerosol dilution and dispersion processes (Gupta and Christopher, 2009b; Benas et al., 2013; Chitranshi et al., 2014). More specifically, RH influences the hygroscopic growth of the particles (Benas et al., 2013), while strong wind speeds affect the PM dispersion (Xiao, 2011) or contribute to additional emissions over arid terrains (Rashki et al., 2012). Furthermore, inclusion of surface temperature for PM estimates has been found to significantly improve the results (Chitranshi et al., 2014; Benas et al., 2013), since temperature may modulate the photochemical reactions and play a major role in the boundary-layer dynamics that control the PM concentrations at the ground via dilution and/or trapping of pollutants (Dumka et al., 2015). In this respect, the atmospheric stability index and boundary layer height (BLH) have been used as surrogates for atmospheric stability resulting in more accurate estimates of PM since the vertical variability of aerosol can be determined (Rohen et al., 2010; Emili et al., 2010). A literature overview (e.g. Hoff and Christopher, 2009) shows that various techniques, such as simple linear regressions (Wang and Christopher, 2003; Engel-Cox et al., 2004), multiple linear regressions (Kanniah et al., 2014b; Chitranshi et al., 2014; Gupta and Christopher, 2009a), nonlinear regressions (Sotoudeheian and Arhami, 2014; Benas et al., 2013), mixed effects models (Kloog et al., 2012; Nordio et al., 2013; Yap and Hashim, 2013; Hu et al., 2014; Xie et al., 2015; Beloconi et al., 2016), statistical and chemical transport models (Van Donkelaar. et al., 2010), as well as complex nonlinear regressions such as Artificial Neural Network (ANN) (Kanniah et al., 2014b; Gupta and Christopher, 2009b) have been applied for PM estimations from space at local, regional and global scales. These advanced statistical techniques significantly improve the prediction capability of the simple AOD-PM relationships that were initially used for PM estimation from space. The continuous renewal and improvement of the databases, methods and techniques for PM monitoring from space justifies the high importance that such studies have for air-pollution mitigation efforts and humanhealth perspectives, especially in the developing countries (Snider et al., 2016).

In Malaysia, the most widely measured air-quality parameter is the $\mathrm{PM}_{10}$. However, the $\mathrm{PM}_{10}$ monitoring network is rather sparse accounting for 74 stations over the whole Malaysian territory of $330,290 \mathrm{~km}^{2}$ and, therefore, $\mathrm{PM}_{10}$ estimates from space are considered as absolutely necessary for warning the local population about the air-quality standards. Nevertheless, no studies covering the entire Malaysian territory have been conducted to map $\mathrm{PM}_{10}$ from space. A recent study by Yap and Hashim (2013) attempted to estimate $\mathrm{PM}_{10}$ over Peninsular Malaysia (only) via a mixed-effects model, which took into consideration the monthly variability of the coefficients (i.e. slope and intercept) in association with MODIS-AOD and $\mathrm{PM}_{10}$. The use of daily measurements of AOD allows for better assessment of space-time interactions than models that only have spatially resolved time invariant land use terms (Kloog et al., 2012) because the relationship between AOD and $\mathrm{PM}_{2.5 / 10}$ varies on daily basis due to differences in mixing height, $\mathrm{RH}$, particle composition, vertical profiles etc. (Lee et al., 2011; Sinha et al., 2015). Moreover, the $\mathrm{PM}_{10}$ concentrations exhibit a remarkable intraseasonal variation at bi-weekly frequencies of 10-20 days (Juneng et al., 2009) over Malaysia and, therefore, the existing model may discount the $\mathrm{PM}_{10}$ daily variation and limits the possibility of studying the acute effects of air pollution. Furthermore, the mixed-effects model may introduce uncertainties with the assumption of linearity and using AOD as the single predictor (Xie et al., 2015). Finally, the model assumes that there is little spatial variability in the relationship, which is not necessarily true especially when the modelling domain gets larger (Hu et al., 2014) as in our study.

Thus, for improving the accuracy of $\mathrm{PM}_{10}$ estimates, the present study integrates atmospheric/meteorological parameters along with advanced statistical methods, i.e., multiple linear regressions (MLR) and $\mathrm{ANN}$, for $\mathrm{PM}_{10}$ monitoring from space for the first time over the whole Malaysian territory. Although a better knowledge has been gained during the last years on the spatial and temporal evolution of aerosols and pollutants over Peninsular Malaysia (Khan et al., 2016a, b), monitoring the aerosol loading and composition over the East Malaysia (Borneo Island) remains a real challenge and not so well documented. There are only 15 ground monitoring stations in this region compared to its size of $198,080 \mathrm{~km}^{2}$. Thus, $\mathrm{PM}_{10}$ estimations via satellite remote sensing is very essential in this region, which is strongly affected by pollution especially during the southwest monsoon. The seasonality of the spatial distribution of $\mathrm{PM}_{10}$ is provided at $10 \times 10 \mathrm{~km}$ spatial resolution during 2007-2011 and is discussed against the potential sources of aerosol and pollutants. The $\mathrm{PM}_{10}$ estimates are validated against ground-based measurements from several stations, while the results are useful for air quality, meteorological and health studies as well as for the calculation of the Environmental Performance Index (EPI) over Malaysia. 


\section{Study area}

Malaysia is a developing country in southeast Asia that undergoes rapid growth in industrial and transportation domains resulting in increase in air pollution and $\mathrm{PM}_{10}$ concentrations during the last decades (Afroz et al., 2003; Jamil et al., 2011). The regional meteorology is characterized by four seasons, namely dry season (June-September), wet season (November-March) and two inter-monsoon seasons (April-May and October, respectively), which are examined separately due to differences in aerosol loading and characteristics. During the dry season, south-westerly winds blow from Indonesia (Sumatra and Kalimantan) carrying biomass-burning aerosols due to extensive forest and agricultural fires (Abas et al., 2004). In contrast, lower levels of aerosol loading are recorded during the rainy season as a result of wet deposition and rainy washout. The winds are mostly from northeastern directions traversing the southern China Sea, while during the two transition seasons, shift of the wind occurs.

\section{Data and methodology}

\subsection{Ground-based datasets}

In Malaysia, the $\mathrm{PM}_{10}$ measurements are collected, processed, analyzed and distributed by a private company known as Alam Sekitar Malaysia Sdn Bhd (ASMA) appointed by the Department of Environment (DOE) and the Malaysian Meteorological Department (METMalaysia). Currently, there are 74 air-quality monitoring stations nationwide (52 continuous air-quality monitoring (CAQM) stations operated by ASMA and 22 stations run by METMalaysia). For the purpose of this study, the following ground-based datasets were used:

\subsection{1. $P M_{10}$ data}

The $\mathrm{PM}_{10}$ concentrations were obtained from the DOE Malaysia covering the period 2007-2011 and correspond to hourly data measured by the beta attenuation monitor (BAM1020) at the 52 stations operated by ASMA. However, only 45 stations (Fig. 1) were selected to be used in this study due to long-term data missing in the rest of the stations. BAM1020 is used for air-quality monitoring in Malaysia since it is capable to record $\mathrm{PM}_{10}$ concentrations (in $\mathrm{mg} \mathrm{m}^{-3}$ or $\mu \mathrm{g} \mathrm{m}^{-3}$ ) on hourly basis by using the beta ray attenuation technique with beta source the ${ }^{14} \mathrm{C}\left(<2.22 \times 10^{6} \mathrm{Beq}\right)$ and half-lifetime of 5730 years (Md.Yusof et al., 2010). Besides that, BAM1020 provides highest level of performance since its accuracy exceeds the U.S. EPA Class III $\mathrm{PM}_{2.5}$ FEM standards for additive and multiplicative bias, while it has low maintenance cost. The instrument operates at a flow rate of 16.71 per minute using a glass fiber filter tape while the measurement resolution is $0.24 \mu \mathrm{g}$ in $1 \mathrm{mg}$ range (Met One Instruments, Inc., 2013). BAM1020 is subjected to errors due to unresolved leaks, such as flow leak or nozzle leak, which need to be kept clean especially in humid areas. The uncertainty of the BAM- 1020 measurements is $\sim 16 \%$, which meets the requirement (25\%) of the Guide to the Demonstration of Equivalence of Ambient Air Monitoring Methods (GDE). The hourly PM $_{10}$ concentrations were analyzed and screened to include the measurements within $\pm 30 \mathrm{~min}$ of the Terra satellite overpass (10.30 am Local Standard Time, LST), and then, were correlated with the MODIS-AOD 550 retrievals. The $\mathrm{PM}_{10}$ measurements from 29 stations were used for the model (MLR and ANN) development and training, while the rest 16 stations were used for the validation of the $\mathrm{PM}_{10}$ estimates from space. Both the "training" and "validation" stations were selected in a way to cover the whole Malaysian territory, i.e., Peninsular Malaysia and Island Malaysia - north part of Borneo - (left and right panels of Fig. 1, respectively), as well as the different meteorological zones of the country and atmospheric environments like urban, rural, industrial, coastal in order to be as representative as possible (see Supplementary Fig. 1 for more details about the land use types around each station). In this way, the group of the "training" stations that was used for the MLR and ANN model developments is as representative as possible for the whole country, while the same exists for the group of stations that used for the model validation. In this way, we also attempted to limit the method's performance and the model's dependence on the selected stations. Initially, the selection of the "training" and "validation" stations was region-specific, i.e., the stations in the Peninsular Malaysia were used for the model training and those in the island Malaysia for the model validation, resulting in similar statistics about model training but lower accuracies in model validation. Therefore, the current selection of the "training" and "validation" stations seems to be more representative for the whole Malaysian territory.

\subsubsection{Meteorological data}

Besides $\mathrm{PM}_{10}$ concentrations, the CAQM stations also provide recordings of several other air pollutants such as $\mathrm{CO}$, tropospheric $\mathrm{O}_{3}$, $\mathrm{NO}_{2}, \mathrm{SO}_{2}$ and meteorological parameters like wind speed, wind direction, ambient temperature and $\mathrm{RH}$. The meteorological data that were used in the analysis correspond to hourly values during the period 2007-2011. Since the ground-based measurements are not able to cover the entire Malaysia, even interpolation cannot provide a promising result (Peng et al., 2006), satellite observations were mostly used. Thus, the measured ambient temperature and $\mathrm{RH}$ data were used for validation of the satellite retrievals and to cross check the satellite estimations of the surface temperature and $\mathrm{RH}$. Similarly to the $\mathrm{PM}_{10}$ data, the ambient temperature and $\mathrm{RH}$ were hourly-averaged around the Terra overpass ( $\pm 30 \mathrm{~min}$ ). Table 1 includes the meteorological
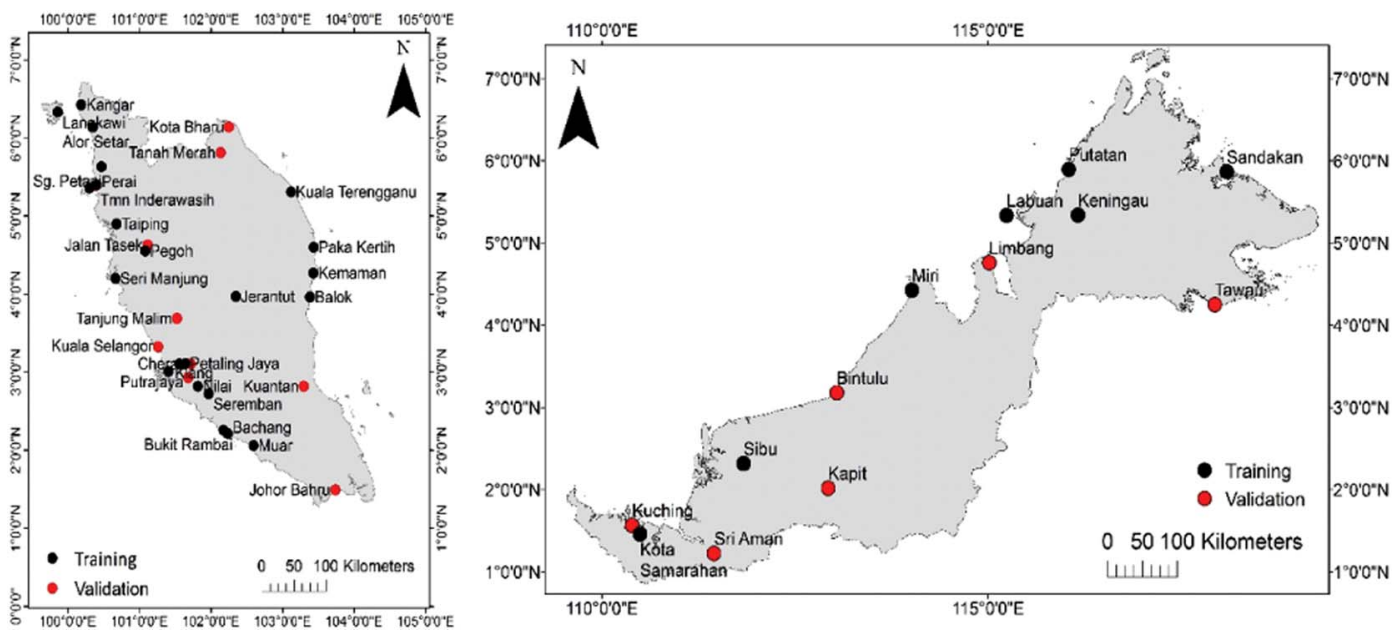

Fig. 1. Locations of the $45 \mathrm{PM}_{10}$ monitoring stations that were used for training (black dots) and validating (red dots) the empirical models developed in this study. 
Table 1

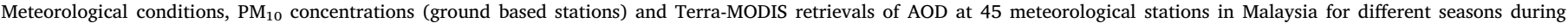
2007-2011. The range of the values are shown in parentheses.

\begin{tabular}{|c|c|c|c|c|}
\hline Parameter & $\begin{array}{l}\text { Dry season } \\
\text { (Jun-Sept) }\end{array}$ & $\begin{array}{l}\text { Wet season } \\
\text { (Nov-March) }\end{array}$ & April-May & October \\
\hline Temperature & $\begin{array}{l}29.65 \pm 0.67 \\
\left(28.21-30.86^{\circ} \mathrm{C}\right)\end{array}$ & $\begin{array}{l}28.07 \pm 1.03 \\
\left(25.61-29.90^{\circ} \mathrm{C}\right)\end{array}$ & $\begin{array}{l}29.64 \pm 0.74 \\
\left(28.10-31.15^{\circ} \mathrm{C}\right)\end{array}$ & $\begin{array}{l}28.70 \pm 0.77 \\
\left(26.97-30.98^{\circ} \mathrm{C}\right)\end{array}$ \\
\hline Relative humidity & $\begin{array}{l}72.51 \pm 4.12 \\
(65.94-79.35 \%)\end{array}$ & $\begin{array}{l}74.85 \pm 6.13 \\
(54.12-86.03 \%)\end{array}$ & $\begin{array}{l}73.33 \pm 4.38 \\
(67.41-83.41 \%)\end{array}$ & $\begin{array}{l}74.53 \pm 3.47 \\
(64.62-79.41 \%)\end{array}$ \\
\hline Wind speed & $\begin{array}{l}6.11 \pm 1.05 \\
(4.40-8.84 \mathrm{~m} / \mathrm{s})\end{array}$ & $\begin{array}{l}6.06 \pm 1.49 \\
(4.59-9.18 \mathrm{~m} / \mathrm{s})\end{array}$ & $\begin{array}{l}6.18 \pm 1.44 \\
(1.46-7.51 \mathrm{~m} / \mathrm{s})\end{array}$ & $\begin{array}{l}5.99 \pm 1.00 \\
(3.17-7.16 \mathrm{~m} / \mathrm{s})\end{array}$ \\
\hline Wind direction & $\begin{array}{l}155.13 \pm 50.28^{\circ} \\
\left(24.75-214.24^{\circ}\right)\end{array}$ & $\begin{array}{l}144.87 \pm 41.95^{\circ} \\
\left(45.88-201.12^{\circ}\right)\end{array}$ & $\begin{array}{l}147.67 \pm 37.03^{\circ} \\
\left(46.87-202.57^{\circ}\right)\end{array}$ & $\begin{array}{l}180.50 \pm 32.74^{\circ} \\
\left(112.23-254.22^{\circ}\right)\end{array}$ \\
\hline $\mathrm{PM}_{10}$ & $\begin{array}{l}50.02 \pm 23.25 \\
\left(23.67-278.49 \mu \mathrm{g} \mathrm{m}^{-3}\right)\end{array}$ & $\begin{array}{l}34.19 \pm 14.03 \\
\left(18.33-169.41 \mu \mathrm{g} \mathrm{m}^{-3}\right)\end{array}$ & $\begin{array}{l}38.24 \pm 13.36 \\
\left(23.03-158.67 \mu \mathrm{g} \mathrm{m}^{-3}\right)\end{array}$ & $\begin{array}{l}43.65 \pm 11.39 \\
\left(27.84-214.77 \mu \mathrm{g} \mathrm{m}^{-3}\right)\end{array}$ \\
\hline MODIS-AOD 550 & $\begin{array}{l}0.52 \pm 0.10 \\
(0.10-1.89)\end{array}$ & $\begin{array}{l}0.41 \pm 0.23 \\
(0.06-1.81)\end{array}$ & $\begin{array}{l}0.42 \pm 0.21 \\
(0.10-1.80)\end{array}$ & $\begin{array}{l}0.59 \pm 0.32 \\
0.10-1.90\end{array}$ \\
\hline Stability (k-index) & $\begin{array}{l}305.22 \pm 25.51 \\
(282.35-320.64 \mathrm{~K})\end{array}$ & $\begin{array}{l}307.01 \pm 21.59 \\
(286.22-321.59 \mathrm{~K})\end{array}$ & $\begin{array}{l}310.74 \pm 5.62 \\
(284.31-320.64 \mathrm{~K})\end{array}$ & $\begin{array}{l}304.38 \pm 43.24 \\
(292.59-320.64)\end{array}$ \\
\hline
\end{tabular}

conditions, along with $\mathrm{PM}_{10}$ concentrations and Terra-MODIS retrievals above the 45 meteorological stations in the four seasons during 2007-2011, in order to reveal the seasonality in meteorological, atmospheric and pollution conditions over Malaysia. The measured wind direction is apparently different in every season and inclusion of this data in the model may improve the prediction of $\mathrm{PM}_{10}$. However, spatial distribution of such data covering entire Malaysia is currently not available, thus only temperature, relative humidity, $\mathrm{k}$ index and MODIS $\mathrm{AOD}_{550}$ were included in the model development.

\subsection{Satellite datasets}

Various products from Terra-MODIS observations over Malaysia were used for the objectives of the current work. MODIS sensor is flown on Terra and Aqua satellites since December 1999 and July 2002, respectively. Due to the wide swath of $2330 \mathrm{~km}$, Terra and Aqua satellites cover the entire Earth surface every 1 to 2 days providing aerosol and atmospheric retrievals at 36 spectral bands from VIS to NIR $(0.41-15.0 \mu \mathrm{m})$ with a spatial resolution ranging between $250 \mathrm{~m}$ and $1000 \mathrm{~m}$ by means of two separate algorithms over land and ocean (Levy et al., 2010; Munchak et al., 2014). Due to its acceptable accuracy $(0.05 \pm 0.15 \times$ AOD), Level 2 (MOD04_L2, $10 \times 10 \mathrm{~km}$ spatial resolution) Terra-MODIS AOD retrievals at $550 \mathrm{~nm}\left(\mathrm{AOD}_{550}\right)$ from Collection 5 (version C005.1) downloaded from http://ladsweb.nascom.nasa. gov/ on daily basis were used in this study during the period 2007-2011. The L2 Terra-MODIS AODs centered above the $\mathrm{PM}_{10}$ stations were correlated with the measured $\mathrm{PM}_{10}$ concentrations for developing models for $\mathrm{PM}_{10}$ monitoring from space. Terra-MODIS atmospheric profile products (MOD07) at 5-km spatial resolution were also used on daily basis in order to obtain the atmospheric stability index (k-index) and surface temperature. The k-index was utilized to estimate the vertical temperature lapse rate and atmospheric static stability that can be used as proxy for the vertical mixing height (Benas et al., 2013). In general, the k-index was derived by using the infrared temperature and moisture profile retrievals in MOD07_L2 product and its values range from $268 \mathrm{~K}$ to $340 \mathrm{~K}$ (NASA, 2015). Especially over Malaysia, the range of k-index was found to be $\sim 287-324 \mathrm{~K}$. The surface temperature was used in the model development for $\mathrm{PM}_{10}$ estimations, since it affects the photochemical reactions and controls the temperature inversions that influence the aerosol concentrations near the surface (Gupta and Christopher, 2009a). The MOD07_L2 product contains retrieved vertical profiles of atmospheric temperature and moisture at 20 vertical levels (Seeman et al., 2006). A clear-sky synthetic regression has been used to estimate the surface skin temperature, while the regression coefficients have been derived using a fast radiative transfer model and atmospheric characteristics from global datasets of radiosonde and model profiles (Seeman et al., 2006). Regression between surface skin temperature measured at Atmospheric Radiation Measurement sites using the downward-looking infrared thermometer and surface air temperature measured using radiosonde was used to estimate/assign the surface skin temperature to all profiles.

The surface temperature data were also used as one of the input parameters for computing the saturation vapour pressure in a way to get the spatial distribution of $\mathrm{RH}$ (see Section 3.3). $\mathrm{RH}$ needs to be computed due to limitation of the meteorological data's spatial coverage and due to the fact that it is not a direct product from the satellite observations. The $\mathrm{RH}$ is included in the codes for $\mathrm{PM}_{10}$ estimations in order to parameterize the hygroscopic growth of particles that modifies the aerosol scattering efficiency and, in turn, the AOD (Wang and Martin, 2007).

As stated above, RH cannot be obtained as a direct satellite product, thus a computation is required (Peng et al., 2006). In this respect, MODIS level 1B calibrated radiances (MOD021 km) were used to retrieve the water-vapour content at NIR via observations at several bands, acting either as non-absorption bands (i.e. band $2(0.865 \mu \mathrm{m})$ and band $5(1.24 \mu \mathrm{m})$ ) or as absorption bands (bands $17(0.905 \mu \mathrm{m}), 18$ $(0.936 \mu \mathrm{m})$ and $19(0.940 \mu \mathrm{m})$ ) (Gao and Kaufman, 2003). Band 17 is a weak absorption channel, which is suitable for retrievals of watervapour content at very humid environments, while the strong absorption channel (band 18) is really suitable for dry areas. These five bands, along with surface temperature data, were used as inputs to compute $\mathrm{RH}$ using the formulas developed by Peng et al. (2006) as detailed out in the methodology Section 3.3. Similarly to $\mathrm{AOD}_{550}$ and MOD07 retrievals, the MOD021 km products were also obtained on daily basis during 2007-2011.

The surface-elevation data from the Shuttle Radar Topography Mission (SRTM) gridded product with $90 \mathrm{~m}$ spatial resolution was used to calculate the air pressure $\left(P_{a}\right)$, since several air pressure data from MODIS (MOD07) retrievals were missing due to cloud cover. The air pressure data are necessary for the estimates of $\mathrm{RH}$, as shown in the next section.

\subsection{Methodology}

\subsubsection{Pre-processing}

Fig. 2 shows the flow chart of the overall methodology adopted for the estimates of $\mathrm{PM}_{10}$ concentrations from space over Malaysia. Initially, we geo-referenced the MODIS $\mathrm{AOD}_{550}$ and the other inputs such as surface temperature, atmospheric stability and $\mathrm{RH}$ to geographic latitude/longitude (WGS84) coordinates. The coordinate system was used by the Global Positioning System and it is intended to be located at the equator. 


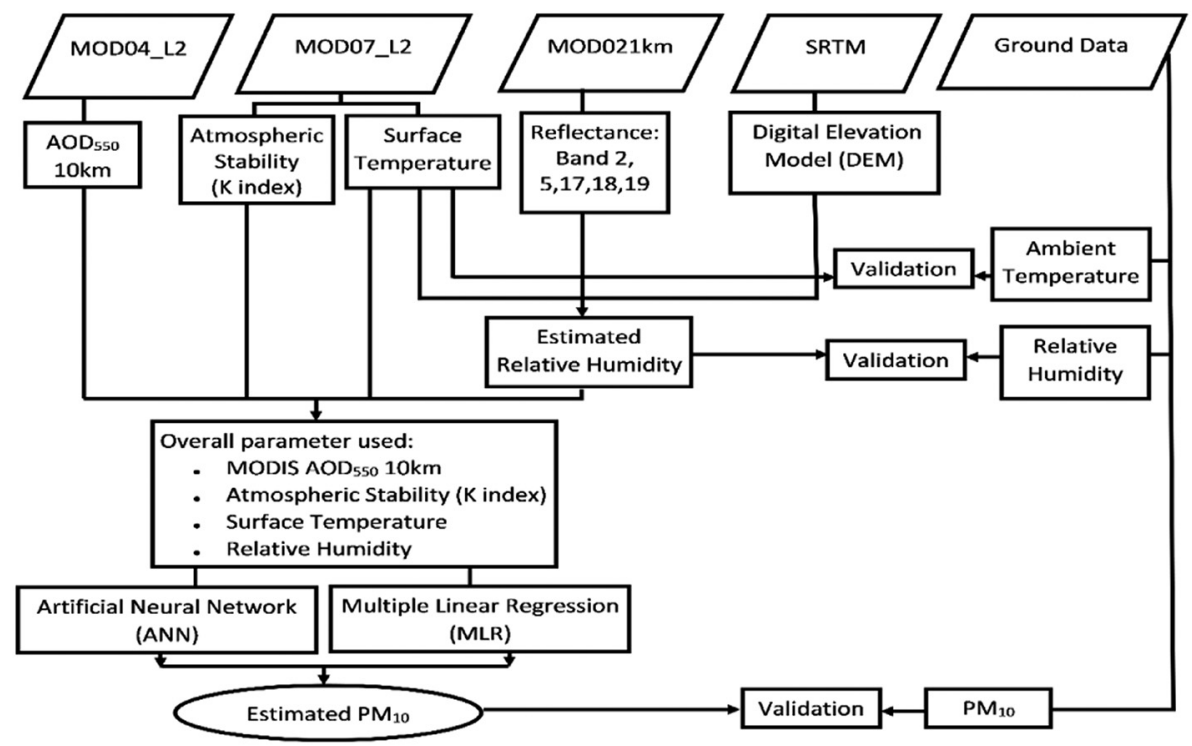

Fig. 2. Flowchart of the overall methodology for $\mathrm{PM}_{10}$ estimation from space over Malaysia.

\subsubsection{Processing}

3.3.2.1. $A O D$ extraction. Initially, the $\mathrm{AOD}_{550}$ values from TerraMODIS retrievals were extracted at $10 \times 10 \mathrm{~km}$. Malaysia is a very challenging environment for $\mathrm{PM}_{10}$ estimates from space because of extensive cloudiness and data missing. To resolve this problem, the spatial-averaged values over a $5 \times 5$ pixels domain $(50 \times 50 \mathrm{~km})$ were used in order to fill the $\mathrm{AOD}_{550}$ data series in the case of missing data (Ichoku et al., 2002); if none of the pixels in the $5 \times 5$ domain has values, these pixels were excluded from the analysis. This technique helped to improve the $\mathrm{AOD}_{550}$ data availability (Kanniah et al., 2014a; Yap and Hashim, 2013).

3.3.2.2. Relative humidity computation. The RH was calculated by using the MOD021km product, particularly bands $2(0.865 \mu \mathrm{m}), 5(1.24 \mu \mathrm{m})$, $17(0.905 \mu \mathrm{m}), 18(0.936 \mu \mathrm{m})$ and $19(0.940 \mu \mathrm{m})$, the MOD07 retrievals of surface temperature, and the elevation data from SRTM via the equations provided by Peng et al. (2006) (Eqs. (1)-(3)). The calculations were performed using a python script in ArcGIS environment.

$\mathrm{RH}=\mathrm{e} / e_{s}$

$e_{s}=611 \exp \left(\frac{17.27 T_{a}}{237.3+T_{a}}\right)$

$\mathrm{e}=\mathrm{Q} * P_{a} / 0.622$

where,

RH: relative humidity

e: $\quad$ vapour pressure

$e_{s}: \quad$ saturation vapour pressure

$T_{a}: \quad$ surface air temperature

$P_{a} \quad$ air pressure

Q: $\quad$ specify humidity

As stated above, the MODIS-AOD 550 retrievals are in spatial resolution of $10 \times 10 \mathrm{~km}$, while the rest of the MODIS-derived meteorological parameters (i.e. surface temperature, $\mathrm{RH}$, atmospheric stability) are considered at $5 \times 5 \mathrm{~km}$ spatial resolution. Therefore, the meteorological parameters were resampled to $10 \mathrm{~km}$ to match the MODIS AOD 550 using the Nearest Neighbor resampling technique. This resampling technique was used because it selects the closest value to the center of the output cell and it does not alter the value of the image cells. Besides that, this simple technique is acceptable to be used to aggregate the spatial resolution since both datasets have the same temporal resolution. For the RH estimations, the $T_{a}$ was obtained from MODIS retrievals, while the $P_{a}$ from the SRTM gridded product at $10 \times 10 \mathrm{~km}$ resolution. The specific humidity (Q) depends on precipitable water vapour (PW) where $\mathrm{PW}$ was computed using the MOD021 km product. Finally, we extracted the Terra-MODIS daily data of $\mathrm{AOD}_{550}$, k-index, surface temperature and $\mathrm{RH}$ above the $\mathrm{PM}_{10}$ and meteorological stations for validation of our retrievals against measured data. These datasets have been used as inputs to develop empirical models for the estimation of $\mathrm{PM}_{10}$ via advanced statistical techniques. It should be noted here, that since $\mathrm{RH}$ has been estimated from the surface temperature retrievals, it is dependent on them and, therefore, cannot be considered as an Independent and Identically Distributed (IID) variable. However, it is used as input for the development of the MLR and ANN models although its inclusion in the multiple linear regressions may cause "co-linearity" phenomenon, but does not affect the model validation results.

3.3.2.3. Regression analysis. Statistical analysis has been performed using both multiple linear regressions (MLR) and non-linear Artificial Neural Network (ANN) regressions in order to attain more accurate $\mathrm{PM}_{10}$ estimations using $\mathrm{AOD}_{550}$ and meteorological parameters as variables. In the linear regression technique, the stepwise approach was applied, which analyses the variables one-by-one and via this way each of the variable's performance or its contribution to the overall model can be easily determined (Benas et al., 2013; Chitranshi et al., 2014). Non-linear techniques are usually used when linear parametric models produce misleading results and high errors (Benas et al., 2013). On the other hand, the Multiple Layer Perceptron (MLP) approach with a back-propagation algorithm was adopted in the ANN non-linear technique. With the development of artificial intelligence technologies, several studies dealing with environmental issues have highlighted the capability of ANN to give accurate predictions of particulate pollution, dust storm detection and AOD retrievals (e.g. Gupta and Christopher, 2009b; Roy, 2012; Yao et al., 2012; Elossta et al., 2013; Han and Sohn, 2013; Xiao et al., 2015). In designing the ANN model, important parameters have to be carefully decided, especially the number of the neurons in the hidden layers, learning rate, momentum and stopping criteria. The ANN consists of interconnected neurons that simplify the non-linear mapping between each set of inputs, as shown in Fig. 3. The MLP is a feed-forward ANN model with at least one layer of hidden neuron whose activation function operates as universal function approximator. With enough 


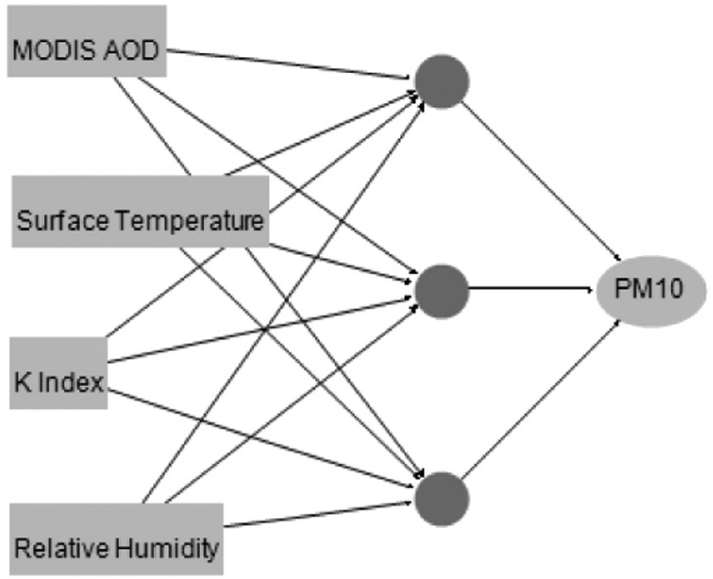

Fig. 3. Architecture of the Multi-Layer Perceptron (MLP) Artificial Neural Network model used for $\mathrm{PM}_{10}$ estimations.

hidden neurons and training data, the ANN models are capable of simulating the mathematical formulas between inputs and outputs (Xiao et al., 2015). In our case, this model consists of three layers (i.e. input, hidden and output) and the sigmoid transfer function (TanH) was used in hidden and output layers. The input layer is composed of four nodes, $\mathrm{AOD}_{550}, \mathrm{RH}, \mathrm{k}$-index and surface temperature derived from MODIS, as predictors, while the output layer is the estimated $\mathrm{PM}_{10}$ (Fig. 3). In this study we used 3 hidden nodes to transform the inputs into output layers. Initially, we started with one hidden node and increased it until optimum results are obtained. The 3 hidden nodes seem to be adequate for the purpose of this study since we have only four inputs (Fig. 3). So far, there is no specific rule to create hidden node even one hidden node is enough for a simple task. However, the usage of many hidden nodes or more complicated models may lead to more precise outputs. In this study, the learning rate and the momentum were fixed at 0.1 ; the learning rate should be in the range of $0-1$, but learning rate values close to 1 will lead to overfit of the data. Momentum is a parameter used to prohibit the model from converging to local minima and high momentum values are able to speed up the convergence of the model. But by setting the momentum too high will cause overshooting of the minimum, which means that the model becomes unstable. Moreover, we specified the number of maximum training iterations as the stopping criteria, meaning that training will stop once the maximum number of iterations is exceeded. The ANN model was trained with 500 iterations and 20 tours; tour is the number of times for restarting the fitting process, since each iteration uses a different random starting point. The algorithm used for the MLP training is based on the steepest descent gradient approach, which is applied in order to minimize the instantaneous error (Ham and Kostanic, 2001; Xiao et al., 2015). According to Gupta and Christopher (2009b), the MLP technique is commonly used in various atmospheric problems that showed directionality of information processing inside the neural network architecture as shown in Fig. 3. However, ANN is expected to provide better predictions because it is capable to analyse the pattern, and at the same time, it minimizes the error functions resulting in improved outputs. The developed MLR and ANN models were calibrated against $\mathrm{PM}_{10}$ measurements at 29 stations distributed all over Malaysia during the period 2007-2011 (see Fig. 1 and Supplementary Fig. 1).

3.3.2.4. Model validation. At the final stage, the $\mathrm{PM}_{10}$ estimations obtained from the developed MLR and ANN models over Malaysia during 2007-2011 were validated against measured $\mathrm{PM}_{10}$ concentrations from 16 stations (Fig. 1). For assessing the model's accuracy in estimating the surface $\mathrm{PM}_{10}$ concentrations, the linear regression analysis and statistical indicators like the Root Mean Square
Error (RMSE) and Mean Bias Error (MBE) were used. The RMSE shows the overall performance of the model in estimating the measured data, while the MBE determines the overestimation or underestimation of the measured $\mathrm{PM}_{10}$ concentrations:

RMSEin $\mu \mathrm{g} \mathrm{m}{ }^{-3}=\sqrt{\frac{\sum_{i=1}^{\mathrm{N}} \mathrm{PM} 10_{\mathrm{m}}-\mathrm{PM}_{1} 0_{e}^{2}}{\mathrm{~N}}}$

$\operatorname{RMSE}($ in $\%)=\frac{\operatorname{RMSE}\left(\text { in } \mu \mathrm{g} \mathrm{m}^{-3}\right)}{\sum_{i=1}^{\mathrm{N}} \mathrm{PM} 10_{\mathrm{m}} / \mathrm{N}} \times 100$

MeanBiasError $(\mathrm{MBE})=\frac{1}{\mathrm{~N}} \sum_{i=1}^{\mathrm{N}} \frac{\mathrm{PM} 10_{\mathrm{e}}-\mathrm{PM} 10_{\mathrm{m}}}{\mathrm{PM} 10_{\mathrm{m}}}$

$\operatorname{MBE}($ in $\%)=\frac{\operatorname{MBE}\left(\text { in } \mu \mathrm{g} \mathrm{m}^{-3}\right)}{\sum_{i=1}^{\mathrm{N}} \mathrm{PM} 10 \mathrm{~m}_{\mathrm{N}} / \mathrm{N}} \times 100$

where, the subscripts $\mathrm{m}$ and e stand for measured and estimated $\mathrm{PM}_{10}$ concentrations respectively, while $\mathrm{N}$ is the total number of data used in the comparisons. Moreover, the Index of Agreement (Willmott, 1981, Willmott et al., 2012) was used to further ensure the model's performance against the surface $\mathrm{PM}_{10}$ measurements as:

$d=1-\frac{\sum_{i=1}^{n}\left(P_{i}-O_{i}\right)^{2}}{\sum_{i=1}^{n}\left(\left|P_{i}-\bar{O}\right|+\left|O_{i}-\bar{O}\right|\right)^{2}}$

where $P i$ and $O_{i}$ are the estimated and measured $\mathrm{PM}_{10}$ concentrations, respectively, while the $\bar{O}$ is the mean value of the measured $\mathrm{PM}_{10}$. Values close to 1 indicate perfect model performance.

\section{Results and discussion}

Before presenting the results of $\mathrm{PM}_{10}$ estimates and validation efforts over Malaysia the spatial distributions (on seasonal basis) and the validation of parameters like $\mathrm{AOD}_{550}, \mathrm{RH}$ and surface temperature that have been used in the intermediate stages for the $\mathrm{PM}_{10}$ estimates (Fig. 2) are examined.

\subsection{Terra-MODIS $A O D_{550}$}

The seasonal-mean $\mathrm{AOD}_{550}$ spatial distributions over Malaysia for the dry and wet seasons are shown in Fig. 4a-d. During the dry season, the $\mathrm{AOD}_{550}$ exhibits high values $(\sim 0.5-1.8)$ over the highly-populated and industrialized regions of the west and south coast of Peninsular Malaysia, while even higher $\mathrm{AOD}_{550}(0.8-1.8)$ is shown over the central-southern parts of Sabah and Sarawak in Island Malaysia (Fig. 4a) due to extensive forest and agricultural fires (Reid et al., 2013). These AODs are at the same magnitude with extreme values observed over environments strongly affected by seasonal forest fires, such as Amazonia (Kambezidis and Kaskaoutis, 2008), African savanna (Eck et al., 2003) northwestern Indo-Gangetic Plains (Kaskaoutis et al., 2014) and Russia (Chubarova et al., 2012). Very high AOD $_{550}$ values above several urban and suburban stations, such as Seri Manjung $(0.96 \pm 0.49)$, Perai $(0.80 \pm 0.31)$, Tawau $(0.82 \pm 0.21)$ were observed during the dry season (Supplementary Fig. 2), which are attributed to heavy traffic and industrial activities along with transported smoke plumes (Kanniah et al., 2014a). In general, the AOD $_{550}$ spatial distribution exhibits lower values during the wet season (Fig. 4b), except for the highly-polluted urbanized sites along the west coast and southern part of Peninsular Malaysia where the AODs remain very high, as well as over USM Penang (Fig. 1) with $\mathrm{AOD}_{550}=0.67 \pm 0.16$. During the wet season, entire Malaysia faces extreme weather conditions with heavy rainfall, especially in the east coast of Peninsular Malaysia and in Sabah and Sarawak (Island Malaysia). However, some extreme AODs ( $>1.4$ ) are observed over 
(a)

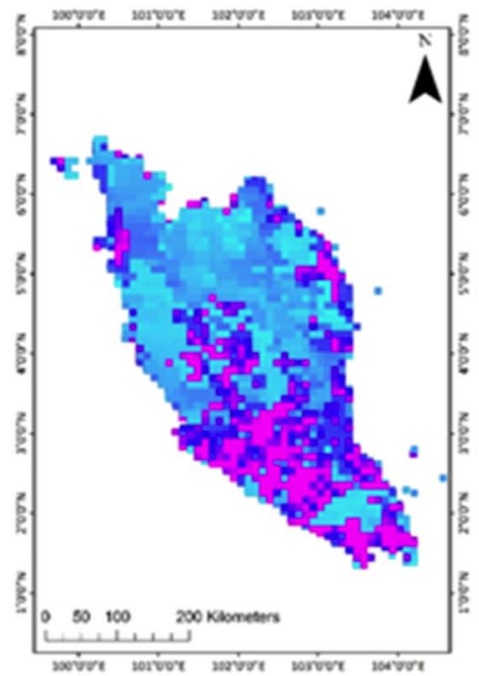

(b)

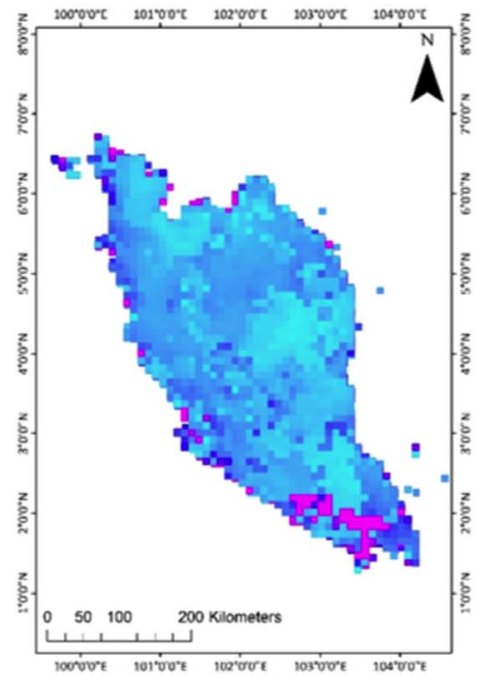

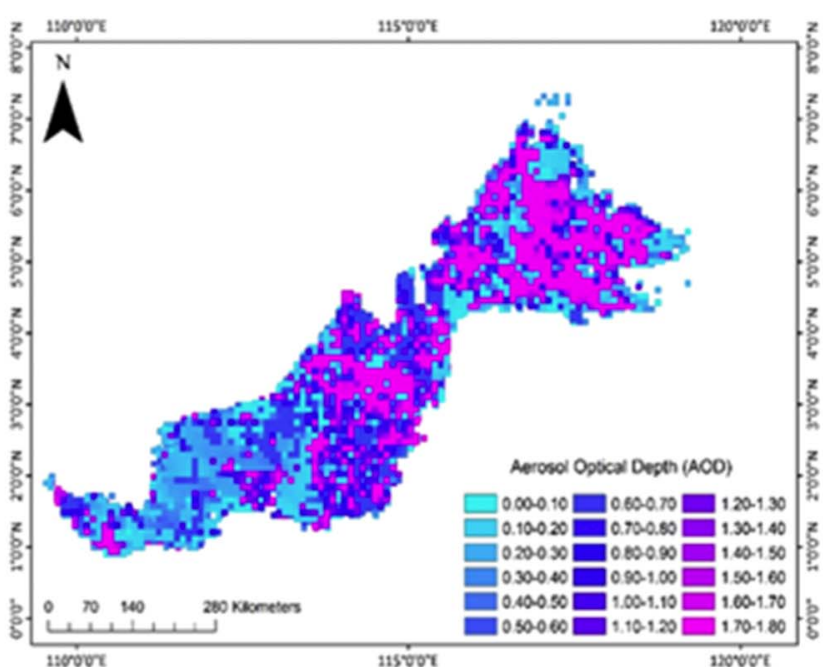

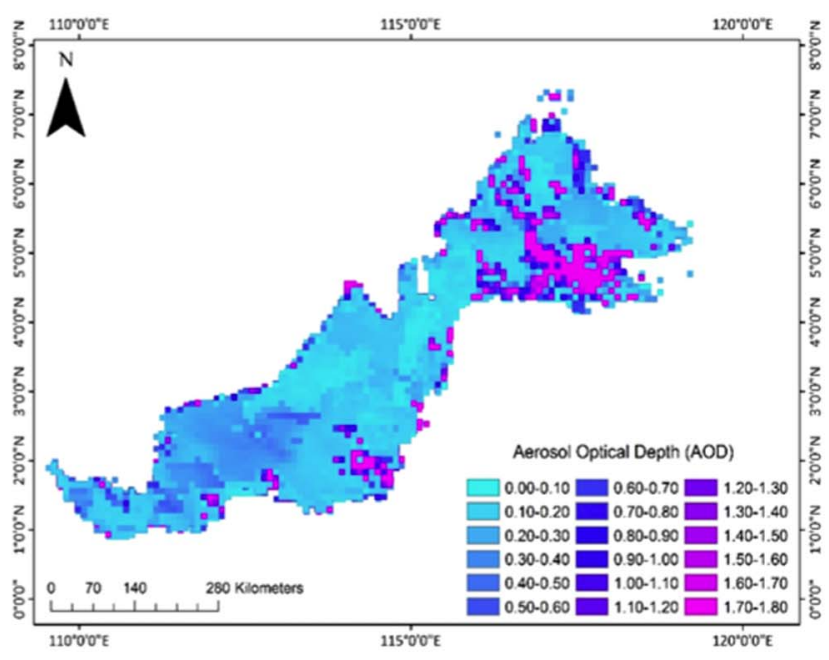

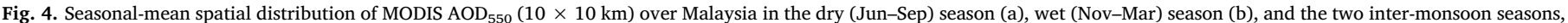
April-May (c) and October (d) during 2007-2011.

certain areas in southern Sabah. It should be noted here that due to the lower data availability as a consequence of the extensive cloudiness and cloud contamination during the wet season, the uncertainty in $\mathrm{AOD}_{550}$ increases compared to the dry season.

During the inter-monsoon (April-May) season (Fig. 4c), the spatial distribution of $\mathrm{AOD}_{550}$ is somewhat similar to that observed in the wet season, with a tendency of increasing $\mathrm{AOD}_{550}$ over some parts of Sabah and Sarawak due to lower moisture and beginning of the agricultural fires (Hyer et al., 2013). However, the most sites located in Sabah and Sarawak (see Fig. 1) exhibit seasonal-mean AOD $_{550}$ mostly below 0.5, especially the rural sites of Kota Samarahan $(0.26 \pm 0.15)$ and Kapit $(0.17 \pm 0.09)$ (Supplementary Fig. 2). In contrast, several sites around the industrial and metropolitan cities, such as Nilai, Balok, Petaling Jaya, Kuantan, USM Penang and Kota Bharu (Fig. 1) exhibit much larger $\mathrm{AOD}_{550}$ values (0.6-0.9) compared to the rest of the stations (Supplementary Fig. 2). The spatial distribution of $\mathrm{AOD}_{550}$ during October (Fig. 4d) indicates that almost the entire Malaysia is covered by a thick aerosol layer with $\mathrm{AOD}_{550}$ of $0.6->1.0$ due to accumulation of aerosol and pollutants, mostly originated from forest and agricultural fires and urban/industrial emissions, during the long dry season (Khan et al., 2016b). Some stations like Shah Alam recorded the highest $\mathrm{AOD}_{550}$ value of $1.40 \pm 0.09$ followed by several stations with mean AOD above 0.8 like Tasek Ipoh (1.18 \pm 0.39$)$, Miri (1.00 \pm 0.04$)$, Tawau (0.98 \pm 0.2830$)$, Petaling Jaya $(0.92 \pm 0.02)$ and Klang
$(0.83 \pm 0.15)$, while numerous other stations exhibit $\mathrm{AOD}_{550}$ in the order of 0.4-0.5 (Supplementary Fig. 2). Similarly to the other seasons, the stations with the highest AODs are located in urban and industrial areas, thus exposed to local sources like vehicle and industrial emissions and open biomass burning (Afroz et al., 2003). On seasonal-mean basis, the MODIS $\mathrm{AOD}_{550}$ is considered as quite representative of the AERONET AOD. In a previous study, Kanniah et al. (2014a) validated the Terra-MODIS AOD retrievals against AOD data from five (Kuching, Tahir, Songkhla, USM_Penang and Singapore) AERONET stations over Malaysia for the period 2007-2011 revealing a satisfactory agreement $\left(\mathrm{R}^{2}=0.55\right)$.

\subsection{Relative humidity}

The seasonal-mean spatial distributions of the $\mathrm{RH}(10 \times 10 \mathrm{~km}$ spatial resolution) calculated using Eqs. (1)-(3) are shown in Fig. 5a-d. In the dry season, the $\mathrm{RH}$ spatial distribution generally exhibits values $<70 \%$, except for forested and mountainous regions in the center of Peninsular Malaysia and in the mangrove areas in south and northern coastal regions (Fig. 5a). The RH remarkably increases during the wet season (Fig. 5b), since the east coast of Peninsular Malaysia, Sabah and Sarawak regions exhibit RH values usually above 70-80\% due to heavy rainfall (Hamdan et al., 2010; Abdullah et al., 2011); Sabah and Sarawak (right plots) also exhibit high $\mathrm{RH}$ values in the 
(c)

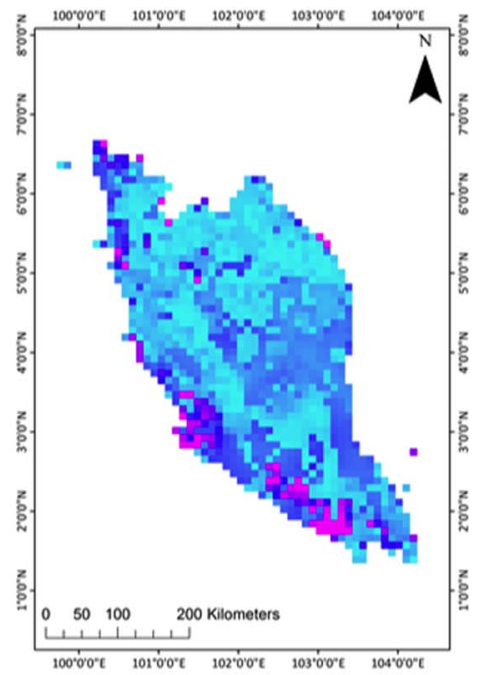

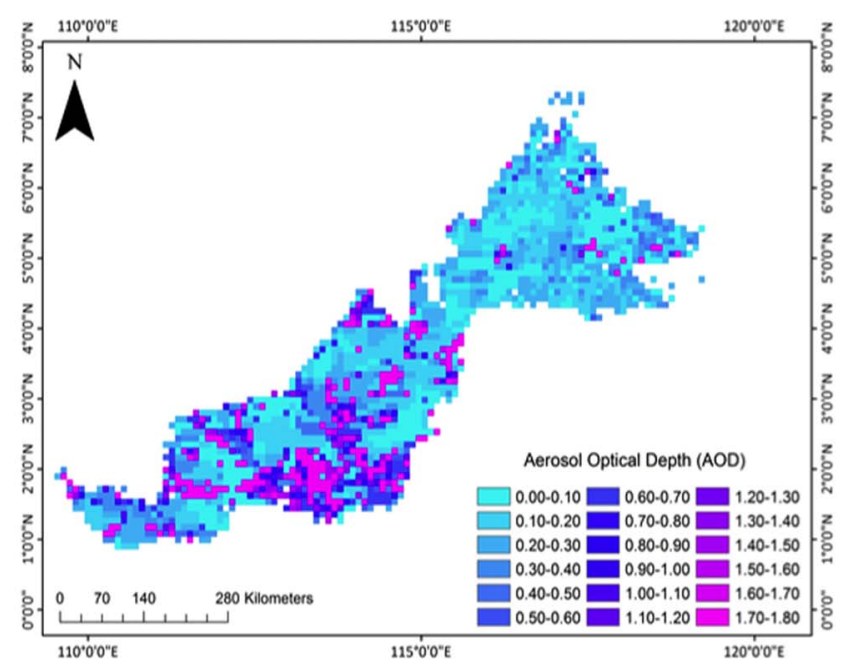

(d)

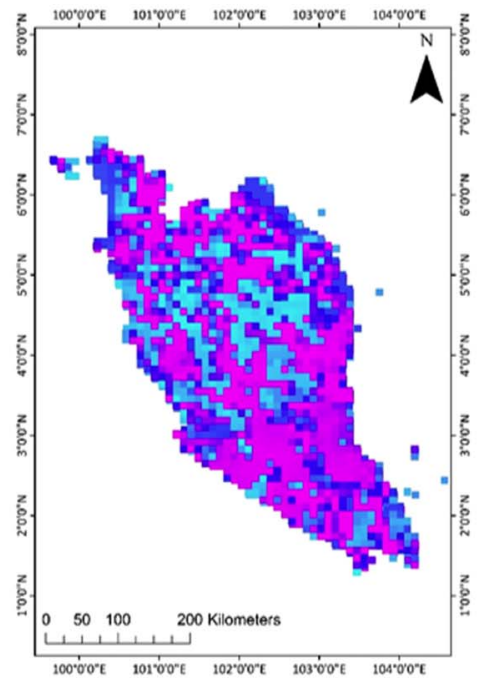

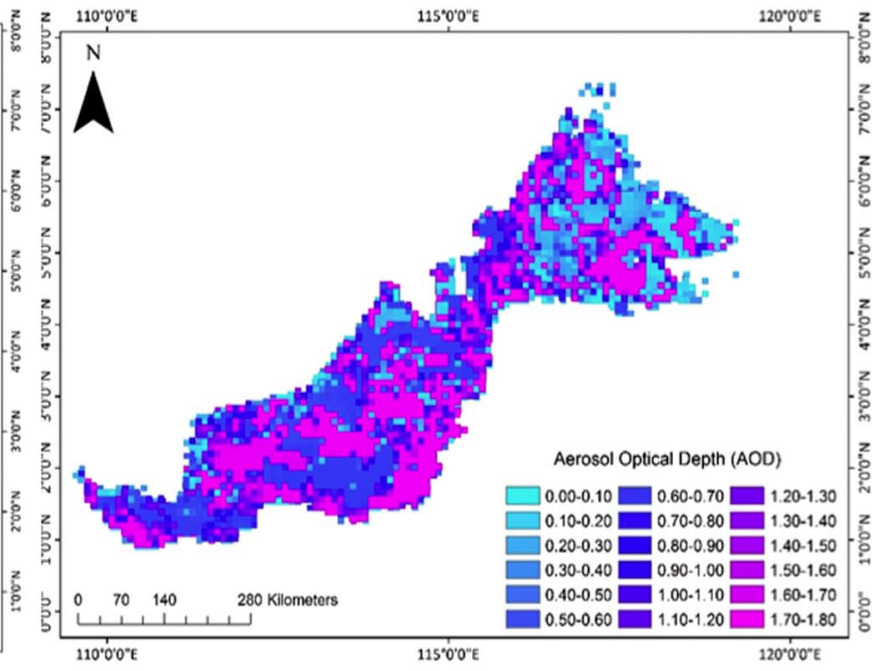

Fig. 4. (continued) range of $60-90 \%$ in the forested areas even in the dry season. Light winds, which scarcely exceed 10 knots, and variable wind directions are responsible for the relatively high $\mathrm{RH}$ values that remained about $\sim 70-80 \%$ in most of the areas over Malaysia during the inter-monsoon season (April-May, Fig. 5c) (Abdullah et al., 2011). The RH distribution during October (Fig. 5d) presents some similarities to that observed in April-May with values above $60 \%$ in Peninsular Malaysia, except for some areas in the west coast where $\mathrm{RH}$ is higher during October, and in the central part of Sabah and Sarawak where the $\mathrm{RH}$ in October is mostly below $50 \%$. The estimated $\mathrm{RH}$ values using remote sensing data have been validated against the measured $\mathrm{RH}$ at the 29 "training" meteorological stations during 2007-2011 (Fig. 6). The comparison was performed by using the averaged $\mathrm{RH}$ values $\pm 30 \mathrm{~min}$ around the Terra overpass time (10:00-11:00 h, LST) in order to avoid any uncertainty from the diurnal variation of $\mathrm{RH}$, while the satellite-derived $\mathrm{RH}$ was centered above each station at $10 \times 10 \mathrm{~km}$ spatial resolution. The regression analysis shows a satisfactory agreement between measured and estimated $\mathrm{RH}$ values with $\mathrm{R}^{2}=0.78$, RMSE $=5.14 \%$ and $\mathrm{MBE}=-0.06 \%$. The data points follow the $1-1$ line, while nearly all are within the observation uncertainties. The satisfactory agreement between estimated and measured $\mathrm{RH}$ values gives credit to the accuracy of the MODIS products and the methodology used for the RH estimations. As stated before, the calculated RH values from the MODIS retrievals do not guarantee IID characteristic for satellite-derived RH. However, the satisfactory agreement with the surface measurements and the same range between measured and estimated RH values (Fig. 6) give further credential to the estimations.

\subsection{Surface temperature}

The seasonal-mean spatial distributions of the surface temperature derived from the MODIS atmospheric profile product are shown in Fig. $7 \mathrm{a}-\mathrm{d}$, revealing a range between $21.8^{\circ} \mathrm{C}$ and $38.8^{\circ} \mathrm{C}$. In general, the urban and highly-populated sites in the west coast of Peninsular Malaysia (Klang, Petaling Jaya, Shah Alam and Penang) as well as the urban/industrialized centers in Sabah and Sarawak (Bintulu, Miri, Keningau, Sandakan and Kuching) exhibit higher values (35.8-38.8 ${ }^{\circ} \mathrm{C}$ ) during the dry season compared to the rural areas and mountainous regions (Fig. 7a). Overall, the influence of the inserted surface-elevation data from SRTM is obvious in the temperature retrievals. The surface temperature during the wet season is remarkably lower than that observed in the dry season due to heavy rainfall, with values ranging between $21.8^{\circ} \mathrm{C}$ and $33^{\circ} \mathrm{C}$ (Fig. 7b). The lowest temperatures in all the seasons are observed at the southern parts of the Island Malaysia, along the borders with Kalimantan (Indonesia), due to elevated terrain and forested-mountainous areas. The maximum surface temperatures during the inter-monsoon (April-May and October) seasons are about $35.8-38.8^{\circ} \mathrm{C}$, with the urban regions to exhibit the highest temperatures of $\sim 36-37^{\circ} \mathrm{C}$ (Fig. $7 \mathrm{c}$, d). In contrast, the mountainous areas in Peninsular Malaysia $\left(24.8-27.8^{\circ} \mathrm{C}\right.$ ) and the rural 

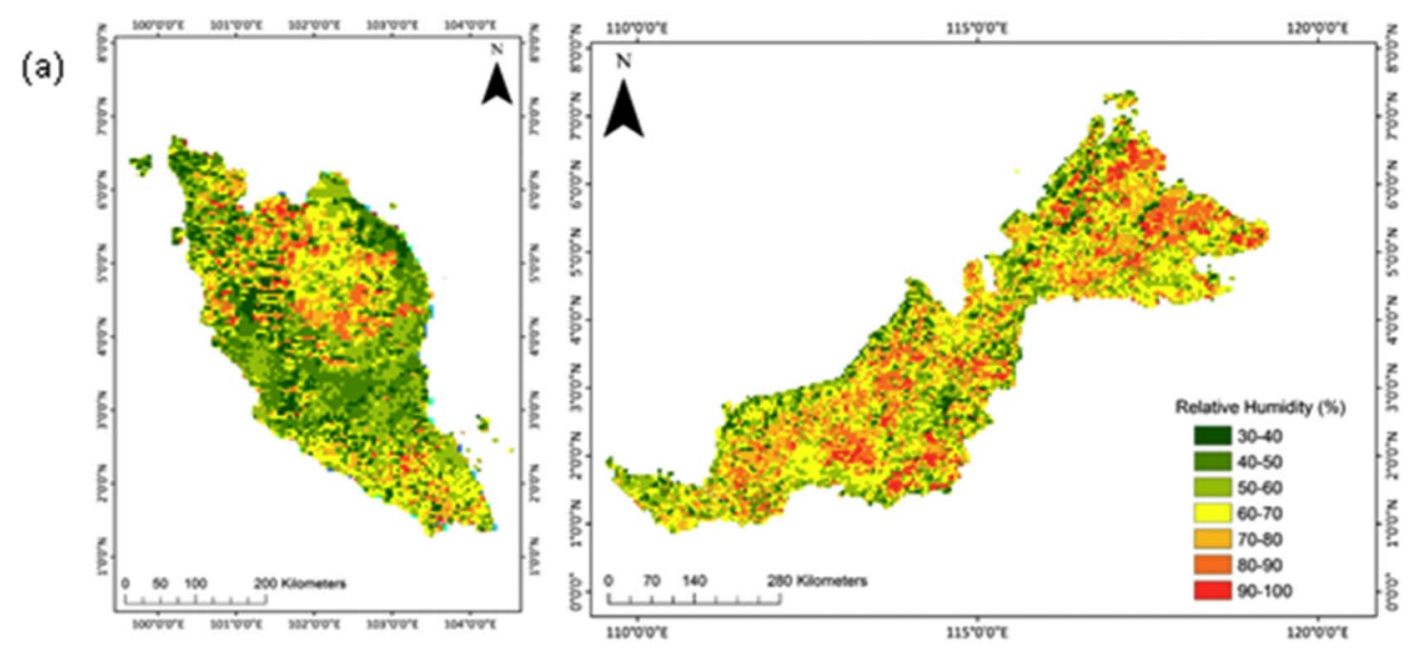

(b)
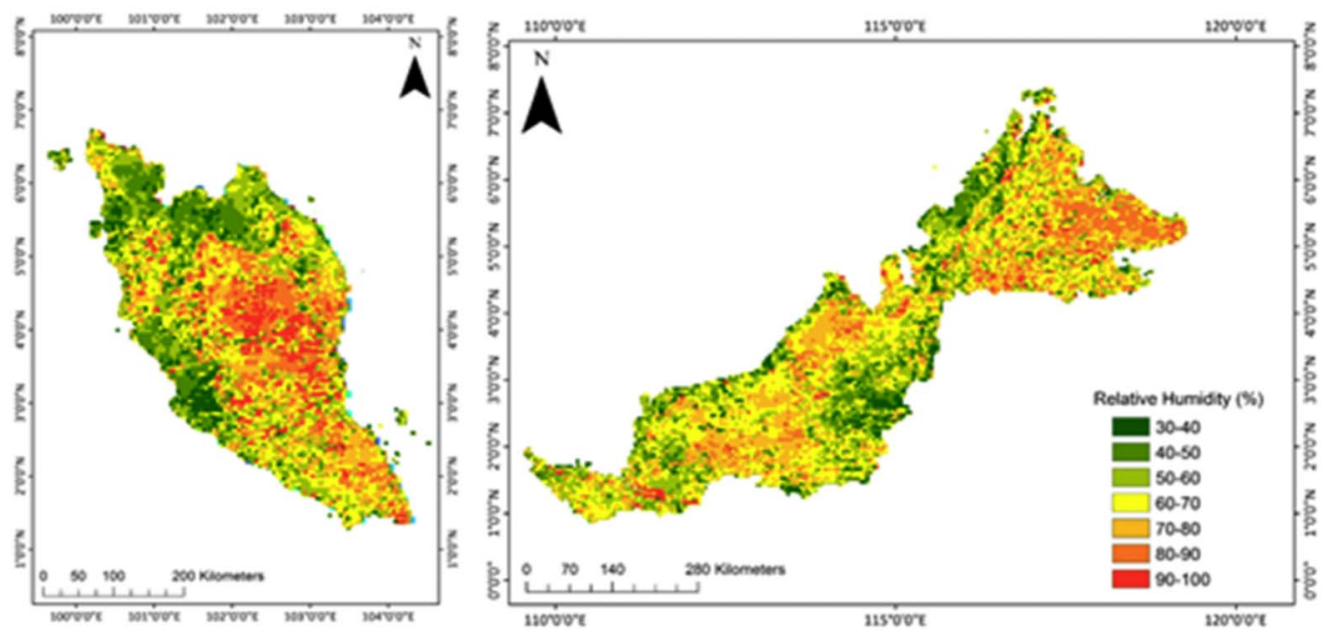

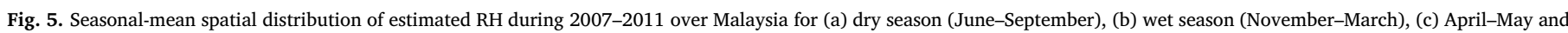
(d) October.

areas in Island Malaysia $\left(21.8-29.8^{\circ} \mathrm{C}\right)$ exhibit the lowest temperatures.

The MODIS-derived surface-temperature values have been validated against measured ambient temperatures at the 29 meteorological stations (Fig. 8). The correlation shows a moderate coefficient of determination $\left(\mathrm{R}^{2}=0.49\right)$, RMSE of $2.68^{\circ} \mathrm{C}(8.73 \%)$ and MBE of $-0.03{ }^{\circ} \mathrm{C}$, and is considered quite satisfactory taking into account that the MODIS-derived surface temperature largely depends on the emissivity of the Earth's surface, whereas the measured ambient temperature $(\sim 2 \mathrm{~m}$ above ground) represents the temperature of the environment. Therefore, the surface temperature that estimated using satellite data may comprise of emissions and thermal absorption from the surface materials, surface moisture, and radiative transfer (thermals) between the surface and the atmosphere (Voogt and Oke, 2003). However, the satellite-derived atmospheric surface temperature may be comparable to the measured ambient temperature under clear skies and/or during atmospheric mixing of any surface-based inversion layers (Kensten et al., 2011). The satisfactory correlation and the fact that $\sim 80 \%$ of the data points lie within the observational uncertainties support the accuracy of the methodology for satellite-derived temperature data over Malaysia and their use as inputs in the developed models.

\subsection{Empirical models for $P M_{10}$ estimation}

Empirical models have been developed for $\mathrm{PM}_{10}$ estimations from space using MODIS AOD 550 , meteorological (surface temperature, $\mathrm{RH}$ ) and atmospheric stability parameters by means of MLR and ANN techniques. The total number of cases that satisfy the criteria (i.e.
$\mathrm{PM}_{10}$ measurements within \pm 30 min of the Terra-MODIS overpass) for $\mathrm{AOD}_{550}$ vs $\mathrm{PM}_{10}$ correlation is 1129 during 2007-2011 (463, 337, 224 and 105 during the dry season, wet season, April-May and October, respectively). The relationship between surface and columnar aerosol properties is a real challenge and can vary substantially due to variations in the aerosol source regions, emission rates and the presence of distinct aerosol layers aloft from different origin and composition (Gupta et al., 2006; Sinha et al., 2015). Furthermore, changes in the mixing-layer height that control the dilution processes may influence the accumulation of near-surface aerosols with negligible effects in the columnar (Sinha et al., 2013; Dumka et al., 2015). The correlation between $\mathrm{PM}_{10}$ and $\mathrm{AOD}_{550}$ (Fig. 9) over the 29 "training" stations is considered satisfactory with $\mathrm{R}^{2}=0.59$ suggesting that satellite AODs can be used for $\mathrm{PM}_{10}$ estimates over Malaysia with an acceptable accuracy. However, for $\mathrm{AOD}_{550}$ values above $\sim 0.6$ and $\mathrm{PM}_{10}$ larger than $\sim 80 \mu \mathrm{g} \mathrm{m}^{-3}$ the scatter of the data points increases indicating higher uncertainty in the $\mathrm{PM}_{10}$ estimations. It should be noted here that similar correlation associated with $53 \%$ of the variance $\left(R^{2}=0.53\right)$ was found between the MODIS AODs and the $\mathrm{PM}_{10}$ over the 45 stations belonging to Peninsular Malaysia, thus indicating similar relationships between $\mathrm{PM}_{10}$ concentrations at the ground and columnar AODs, nearly independently from the group of the selected stations.

High correlations between the surface $\mathrm{PM}_{10}$ concentrations and columnar $\mathrm{AOD}_{550}$ were observed in each season, with $\mathrm{R}^{2}$ values ranging from 0.51 (wet season) to 0.71 (October), which are much above those $\left(\mathrm{R}^{2}\right.$ between 0.16 and 0.71 and mostly around 0.3 ) found between surface $\mathrm{PM}_{2}$ (PM below $2 \mu \mathrm{m}$, measured by a Quartz Crystal 
(c)

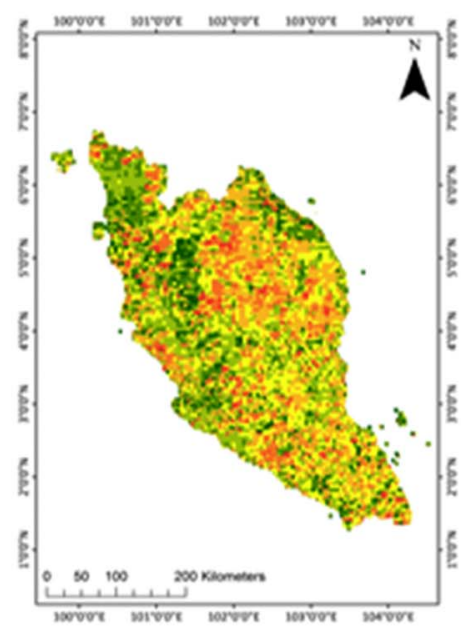

(d)

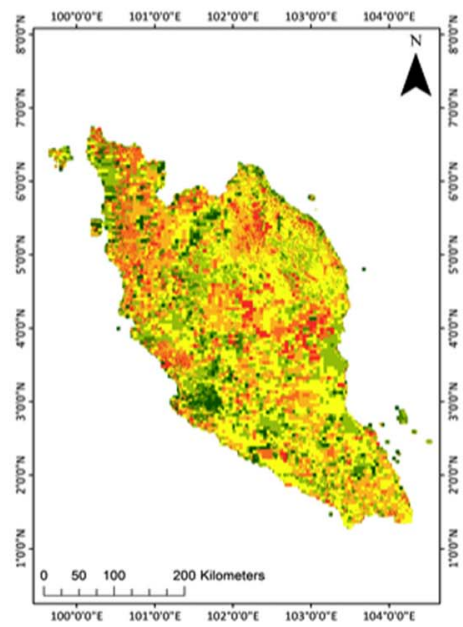

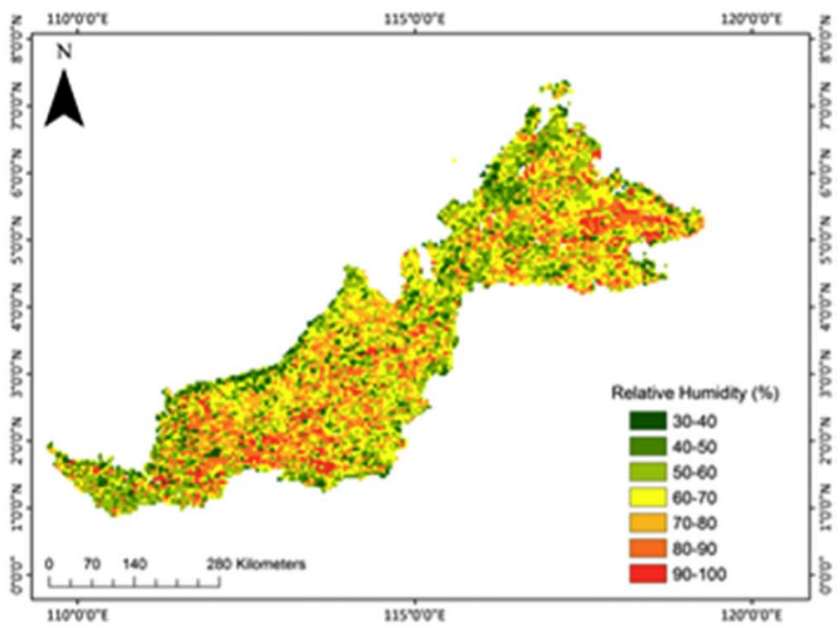

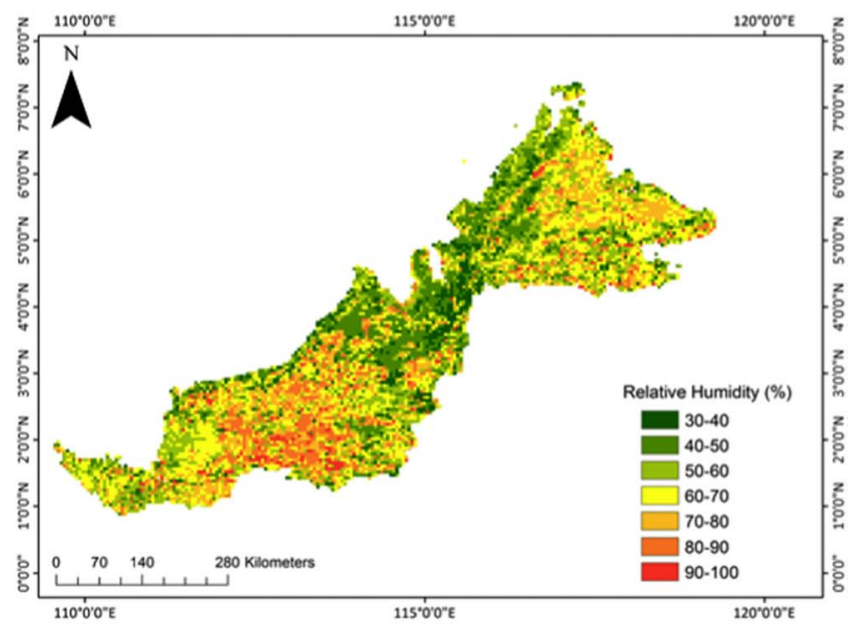

Fig. 5. (continued)

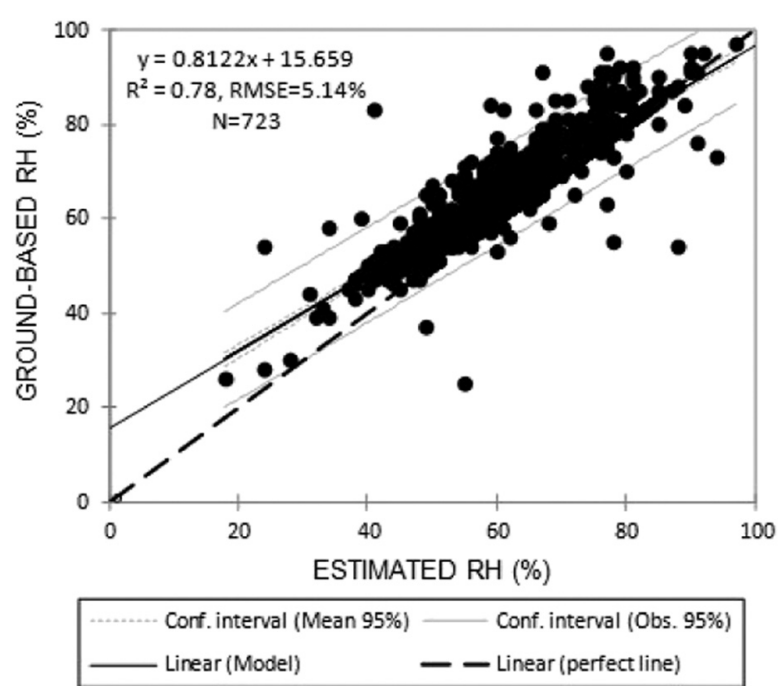

Fig. 6. Correlation between estimated and measured $\mathrm{RH}$ values at the 29 meteorological stations that used for model calibration over Malaysia during 2007-2011.

Microbalance instrument) and columnar (MODIS and Microtops-II) AODs over Hyderabad, India (Sinha et al., 2015). Furthermore, the $\mathrm{R}^{2}=0.59$ (Fig. 9) is comparable or even higher than respective values obtained from several studies over the globe dealing with AOD vs PM relationship (see Table 2). Table 2 summarizes the satellite datasets and other input parameters as well as the various techniques that have been used at several locations worldwide for PM estimations from space. Note that the accuracy of the $\mathrm{PM}_{10}$ estimations via both MLR and ANN techniques over Malaysia is found to be comparable or even larger compared to other studies. On the other hand, changes in the physicalchemical properties of aerosols may also affect the $\mathrm{PM}_{10}$ vs $\mathrm{AOD}$ relationship, since these properties control the scattering and absorption processes in the atmosphere and, therefore, the AOD and its spectral variation (Valenzuela et al., 2015). Especially over Malaysia, the elevated aerosol plumes (1-2 km), mostly composed by biomassburning smoke and anthropogenic pollution transported either from southeast Asia or Indonesia (Campbell et al., 2013; Wang et al., 2013), may weaken the relationship between near-surface and columnar aerosols, thus considering the $\mathrm{PM}_{10}$ estimates from space a real challenge.

Although Fig. 9 revealed a satisfactory correlation between MODIS $\mathrm{AOD}_{550}$ and surface $\mathrm{PM}_{10}$ concentrations over the 29 stations used for model training, the inclusion of the meteorological parameters (surface temperature, $\mathrm{RH}, \mathrm{k}$-index) in the developing models may improve the $\mathrm{PM}_{10}$ estimations, as has been also seen in several previous studies (see Table 2). The developed MLR model for the $\mathrm{PM}_{10}$ estimations over Malaysia based on the 29 selected "training" stations is:

$\begin{aligned} \mathrm{PM}_{10}= & 268.51+\left(56.19 * \mathrm{AOD}_{550}\right)+(1.30 * \text { surface temperature })+(-0.86 \\ & * \mathrm{k} \text { index })+(-0.26 * \mathrm{RH})\end{aligned}$

It should be noted that the selection of different group of stations (e.g., stations only over the Peninsular Malaysia) results is slight 

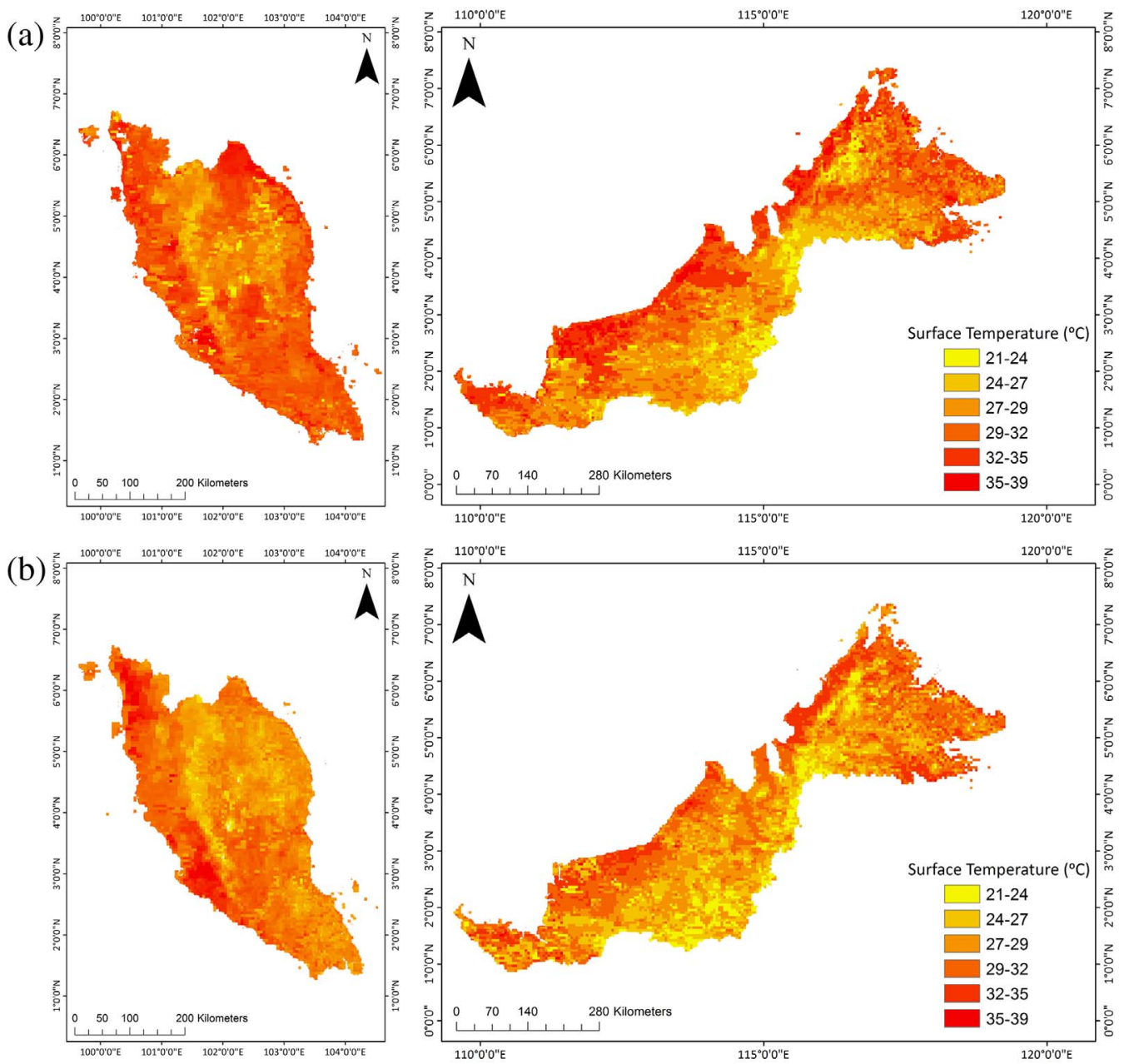

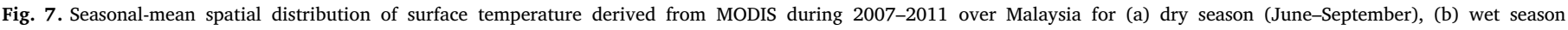
(November-March), (c) inter-monsoon (April-May) and, (d) inter-monsoon (October).

modifications in the constant terms for each variable, but the final evaluation against measured $\mathrm{PM}_{10}$ leads to similar statistics $\left(\mathrm{R}^{2}\right.$, RMSE, MBE). Furthermore, it should be reminded that the RH cannot be considered as IID variable, and therefore, via Eqs. (1) and (2), this model (Eq. (5)) is not linear for the surface temperature. The evaluation of this model has been performed against the measured $\mathrm{PM}_{10}$ concentrations at the 29 "training" stations with total availability of $\mathrm{N}=723$ data. The correspondence of each variable included in Eq. (5) on $\mathrm{PM}_{10}$ estimations was determined by the stepwise technique and the results are summarized in Table 3. The MLR technique reveals that the accuracy of the $\mathrm{PM}_{10}$ estimates increases when all the four variables are included in the parameterization scheme $\left(\mathrm{R}^{2}=0.66\right.$ and $\mathrm{RMSE}=12.39 \mu \mathrm{g} \mathrm{m}^{-3}, \quad$ RMSE $\quad(\%)=25.95 \%, \quad$ MBE $=-$ $0.0004 \mu \mathrm{g} \mathrm{m}^{-3}$ ) compared to the cases that a single variable was included (Table 3). Stepwise analysis with the individual RH values was avoided, since it depends on surface temperature.

As expected, $\mathrm{AOD}_{550}$ is found to have the highest correlation $\left(\mathrm{R}^{2}=0.59\right)$ and lowest RMSE $\left(13.61 \mu \mathrm{g} \mathrm{m}^{-3}\right)$ among the variables regarding the $\mathrm{PM}_{10}$ estimates. The MODIS $\mathrm{AOD}_{550}$ results in better prediction of the $\mathrm{PM}_{10}$ concentrations compared to previous analysis using MERIS AOD over Malaysia (Kanniah et al., 2014b), suggesting that the coarser spatial resolution of MODIS is more suitable for estimating $\mathrm{PM}_{10}$ for altitudes $<2 \mathrm{~km}$ (Munchak et al., 2014; Levy et al., 2013). The finer resolution of AOD retrievals provides errors in the pixel selection, especially over the urban areas due to the heterogeneity of land surface, although it is capable to monitor $\mathrm{PM}_{10}$ at local scales (Munchak et al., 2014). The second best predictor of $\mathrm{PM}_{10}$ using the MLR technique is the atmospheric stability (k-index) with $\mathrm{R}^{2}=0.16$ and $\mathrm{RMSE}=19.44 \mu \mathrm{g} \mathrm{m}^{-3}$. The inclusion of this parameter considerably improves the $\mathrm{PM}_{10}$ estimations, similarly to the findings by Gupta and Christopher (2009a) who used the BLH as a surrogate to estimate the height of the aerosol layer, resulting in a slight improvement of the correlations from $\mathrm{R}=0.66$ to $\mathrm{R}=0.67$. Similarly, Benas et al. (2013) found that the inclusion of the atmospheric stability in the parameterization scheme slightly increased the $\mathrm{R}^{2}$ from 0.67 to 0.71 . According to Benas et al. (2013), the k-index considers both the horizontal and vertical aerosol mixing within the $10 \mathrm{~km} \times 10 \mathrm{~km}$ of MODIS spatial resolution, since the surface layer is generally affected by turbulent movement (unstable conditions). However, other studies (Seo et al., 2015; Emili et al., 2010) found that the BLH, which strongly affects the aerosol vertical profile, showed a better agreement with $\mathrm{PM}_{10}$ estimations. The $\mathrm{RH}$ takes place in the aerosol hygroscopic growth factor and may influence the particle composition and optical properties of aerosols, mainly the scattering process (Malm et al., 2000; Titos et al., 2014), while a negative correlation with $\mathrm{PM}_{10}$ was found according to the developed MLR model (Eq. (5)), similarly to that obtained by Seo et al. (2015) and Emili et al. (2010). However, as a calculated parameter via MODIS surface-temperature, the RH values may not fully explain the impact of "real $\mathrm{RH}$ " on $\mathrm{PM}_{10}$ estimations. The surface temperature may influence the photochemical reactions in the atmosphere and favors the formation of secondary aerosol (Sheehan and Bowman, 2001; Takekawa et al., 2003). Although the surface temperature exhibits very low correlation with $\mathrm{PM}_{10}\left(\mathrm{R}^{2}=0.11\right.$, RMSE $=20.08 \mu \mathrm{g} \mathrm{m}^{-3}$ ), other studies found significant influence of 
(c)

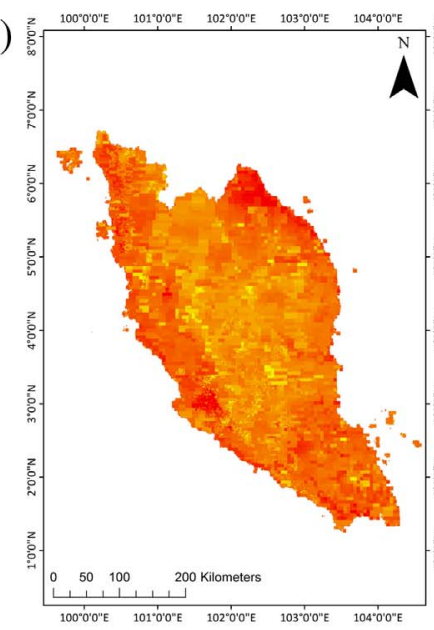

(d)

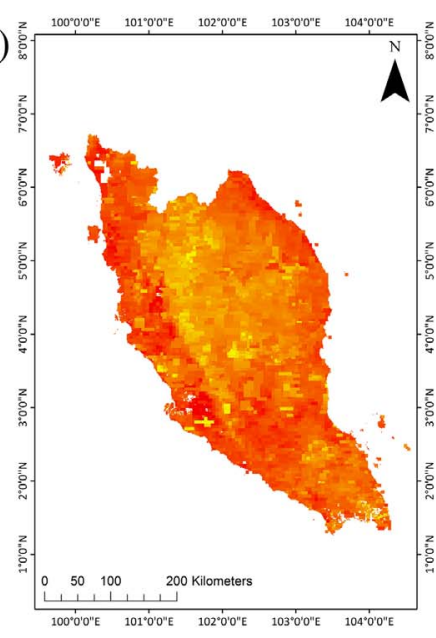

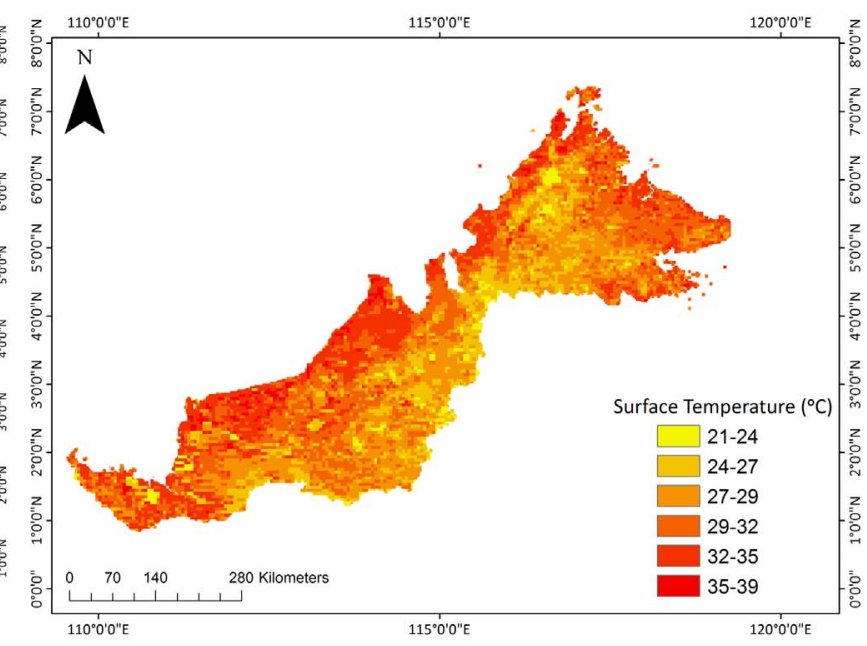

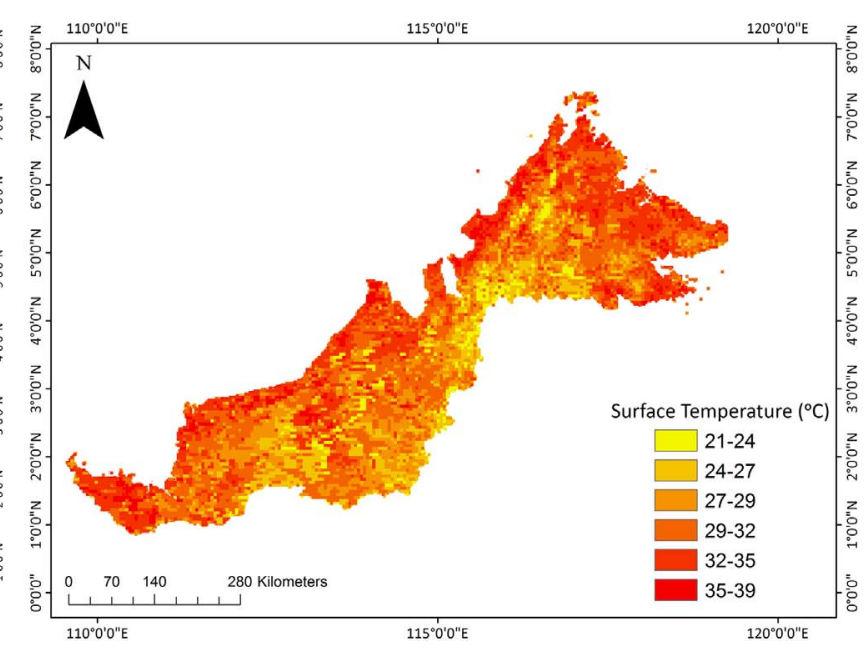

Fig. 7. (continued)

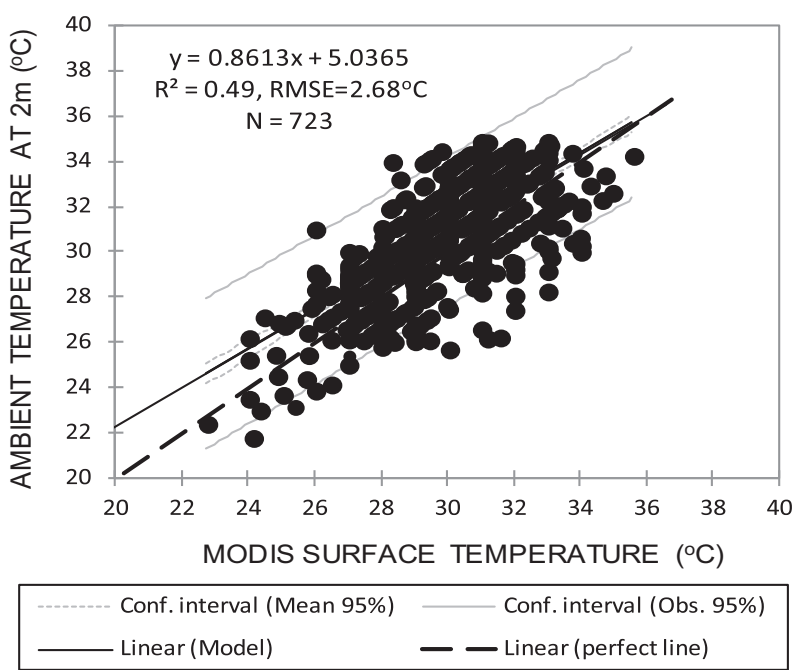

Fig. 8. Correlation between the MODIS-derived surface-temperature product and measured temperatures at $2 \mathrm{~m}$ above ground at the 29 "training" meteorological stations over Malaysia during 2007-2011.

surface temperature on the $\mathrm{PM}_{10}$ estimates (Benas et al., 2013; Barmpadimos et al., 2011). Besides that, the very high humidity levels in southeast Asia may reduce the effect of the surface temperature. In summary, the analysis reveals that the $\mathrm{AOD}_{550}$ exhibits a satisfactory correlation with the $\mathrm{PM}_{10}$ measurements, since aerosols are usually well mixed within the lower boundary layer in the absence of distinct

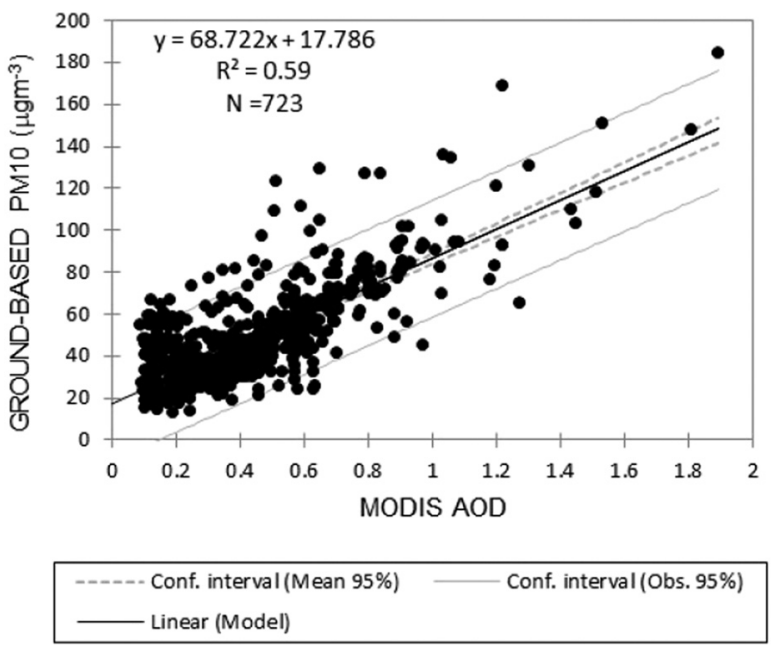

Fig. 9. Correlation between Terra-MODIS $\mathrm{AOD}_{550}$ and ground-based $\mathrm{PM}_{10}$ concentrations obtained at the 29 "training" stations over Malaysia.

aerosol layers aloft; however, the inclusion of the meteorological parameters and stability index improves the accuracy of the $\mathrm{PM}_{10}$ estimates.

As far as the ANN technique is concerned, the empirical model developed for estimating the $\mathrm{PM}_{10}$ concentrations based on data over the 29 "training" stations is:

$\mathrm{PM}_{10}=72.599+(39.399 * \mathrm{H} 1)+(-31.944 * \mathrm{H} 2)+(-30.735 * \mathrm{H} 3)$ 


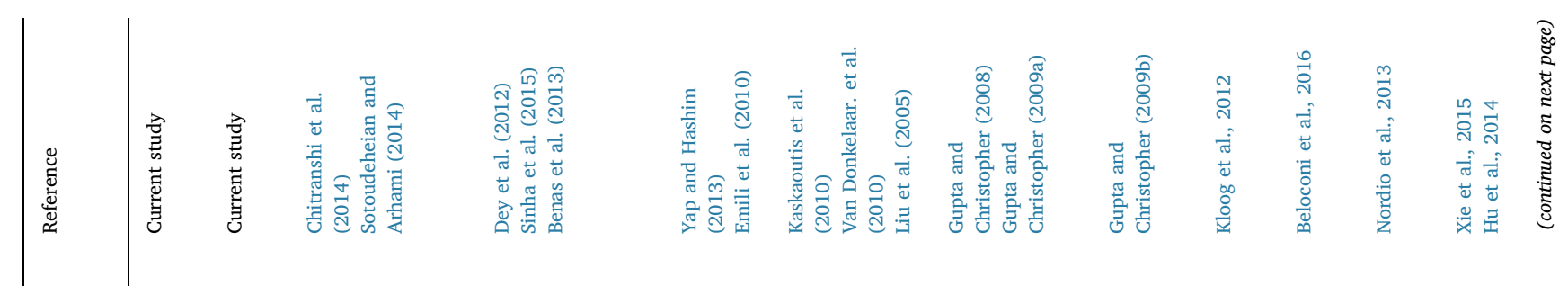
WUW :

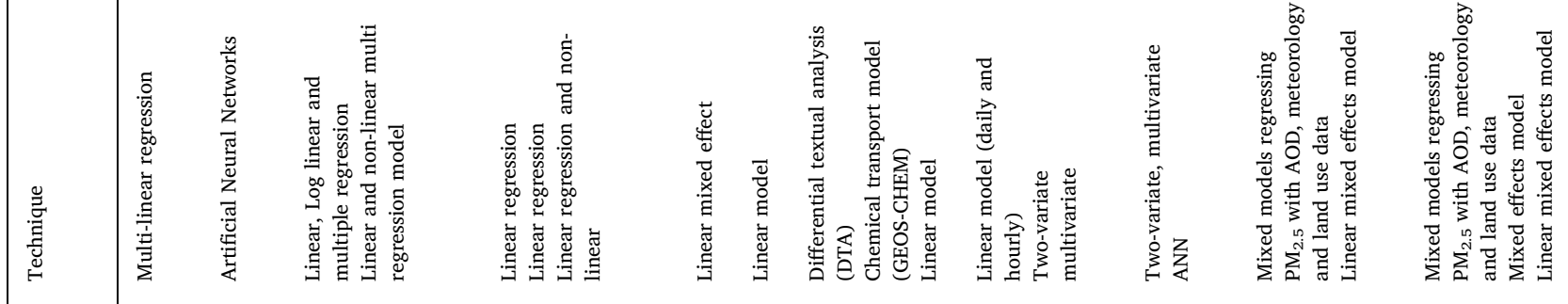

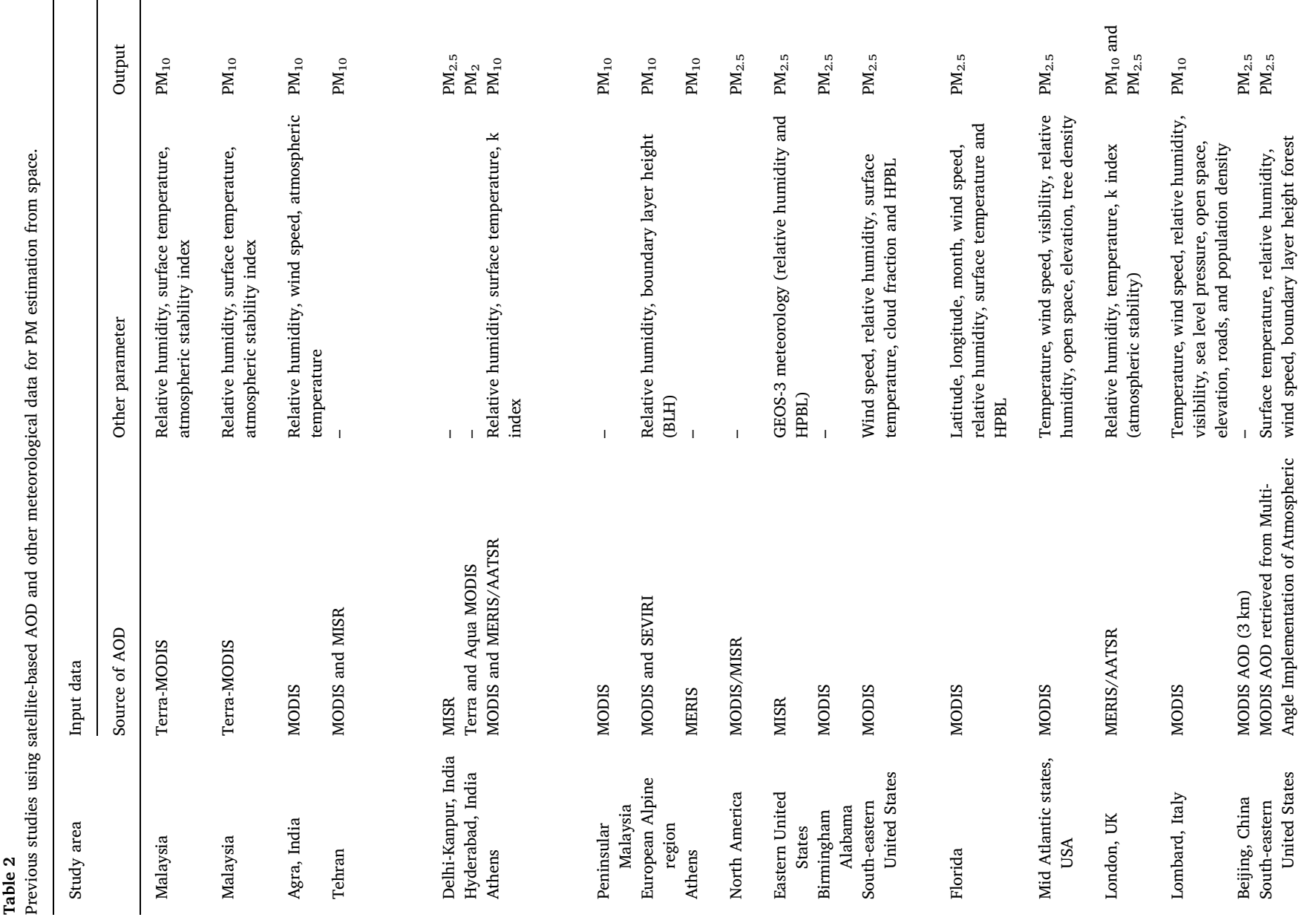


Table 3

Determination coefficient $\left(\mathrm{R}^{2}\right)$, RMSE, MBE and index of agreement values using multiple linear regression (stepwise) implementation for $\mathrm{PM}_{10}$ estimations. The comparison has been made between estimated and measured $\mathrm{PM}_{10}$ concentrations at the 29 stations used for model training.

\begin{tabular}{|c|c|c|c|c|c|}
\hline $\begin{array}{l}\text { Parameter(s) used } \\
\text { for } \mathrm{PM}_{10} \text { estimation }\end{array}$ & $\mathrm{R}^{2}$ & $\begin{array}{l}\text { RMSE } \\
\left(\mu \mathrm{g} \mathrm{m}^{-3}\right)\end{array}$ & $\begin{array}{l}\mathrm{MBE} \\
\left(\mu \mathrm{g} \mathrm{m}^{-3}\right)\end{array}$ & $\begin{array}{l}\text { Index of } \\
\text { agreement }\end{array}$ & p-Value \\
\hline $\mathrm{AOD}_{550}$ & 0.59 & 13.61 & -0.002 & 0.85 & $1.55 \mathrm{E}-96$ \\
\hline Surface temperature & 0.11 & 20.08 & 0.0002 & 0.32 & $1.63 \mathrm{E}-13$ \\
\hline $\begin{array}{l}\text { Atmospheric } \\
\text { stability (k- } \\
\text { index) }\end{array}$ & 0.16 & 19.44 & 0.003 & 0.44 & $1.64 \mathrm{E}-20$ \\
\hline $\begin{array}{c}\mathrm{AOD}_{550}, \mathrm{RH}, \text { surface } \\
\text { temperature }\end{array}$ & 0.63 & 12.94 & -0.035 & 0.87 & $1.66 \mathrm{E}-108$ \\
\hline $\begin{array}{c}\mathrm{AOD}_{550}, \mathrm{RH}, \text { surface } \\
\text { temperature, } \\
\text { atmospheric } \\
\text { stability }\end{array}$ & 0.66 & 12.39 & -0.0004 & 0.89 & $1.55 \mathrm{E}-117$ \\
\hline
\end{tabular}

where: $\mathrm{H}=$ hidden layers and

$$
\begin{aligned}
\mathrm{H} 1= & \mathrm{TANH}(0.5 *((-67.612)+(7.216 * \mathrm{AOD})+(-0.243 \\
& * \text { surface temperature })+(0.214 * \mathrm{k} \text { index })+(0.058 * \mathrm{RH}))) \\
\mathrm{H} 2= & \mathrm{TANH}(0.5 *((-76.084)+(3.464 * \mathrm{AOD})+(-0.319 \\
& * \text { surface temperature })+(0.254 * \mathrm{k} \text { index })+(0.057 * \mathrm{RH}))) \\
\mathrm{H} 3= & \mathrm{TANH}(0.5 *((-32.739)+(-0.667 * \mathrm{AOD})+(-0.169 \\
& * \text { surface temperature })+(0.114 * \mathrm{k} \text { index })+(0.075 * \mathrm{RH})))
\end{aligned}
$$

The ANN technique produces similar or slightly better estimations of the $\mathrm{PM}_{10}$ concentrations compared to MLR, as shown from the statistical indicators in Table 4, which were computed from the comparison between measured and estimated $\mathrm{PM}_{10}$ concentrations at the 29 "training" stations (Fig. 1). Therefore, the ANN model slightly improves the $\mathrm{R}^{2}$ from 0.66 (Table 3) to 0.71 (Table 4) and the RMSE from $12.39 \mu \mathrm{g} \mathrm{m}^{-3}$ in the MLR model to $11.61 \mu \mathrm{g} \mathrm{m}^{-3}(24.32 \%)$ in the ANN. A slightly different ANN model developed based on the 45 stations over the Peninsular Malaysia resulted in similar $\mathrm{R}^{2}=0.73$ after comparison with the measured $\mathrm{PM}_{10}$.

\subsection{Model validation}

The ability of both developed models (MLR and ANN) in predicting the $\mathrm{PM}_{10}$ concentrations over Malaysia was examined via comparisons against measured $\mathrm{PM}_{10}$ concentrations at the 16 stations used for model validation. The correlation between measured and estimated $\mathrm{PM}_{10}$ via the MLR model (Eq. (5)) exhibits a moderate but statistically significant correlation at $95 \%$ confidence level $\left(\mathrm{R}^{2}=0.56\right.$, $\mathrm{p}$-value $<0.05$, RMSE $=10.58 \mu \mathrm{g} \mathrm{m}^{-3} \quad(24.28 \%), \quad$ and $\mathrm{MBE}=0.04 \mu \mathrm{g} \mathrm{m}^{-3}$ ) (Fig. 10a). The ANN model (Eq. (6)) very slightly improves the $\mathrm{PM}_{10}$ estimations compared to MLR with $\mathrm{R}^{2}=0.58, \mathrm{RMSE}=10.16 \mu \mathrm{g} \mathrm{m}^{-3}$ $(23.31 \%)$ and $\mathrm{MBE}=0.05 \mu \mathrm{g} \mathrm{m}^{-3}$. Similarly to our findings, Gupta and Christopher (2009b) found that ANN model improves the PM estimates compared to general linear models, such as the multivariate model. Nearly all the data points are well within the $95 \%$ confidence

Table 4

Statistical results of the ANN model used for $\mathrm{PM}_{10}$ estimations at the 29 training stations over Malaysia.

\begin{tabular}{ll}
\hline Parameter & Training data \\
\hline $\mathrm{R}^{2}$ & 0.71 \\
$\mathrm{RMSE}\left(\mu \mathrm{g} \mathrm{m}^{-3}\right)$ & 11.61 \\
$\mathrm{MBE}\left(\mu \mathrm{g} \mathrm{m}^{-3}\right)$ & -0.03 \\
Index of agreement & 0.90 \\
$\mathrm{~N}$ & 723 \\
\hline
\end{tabular}




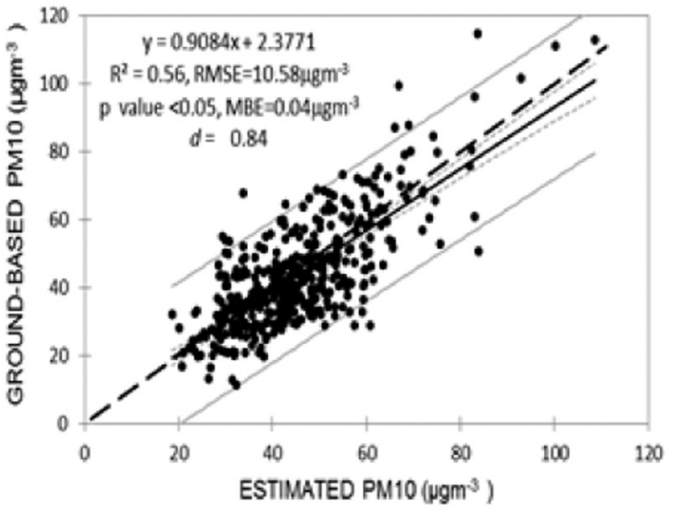

(a)

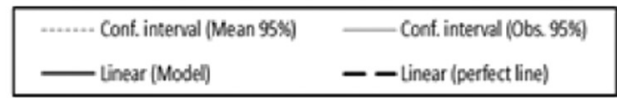

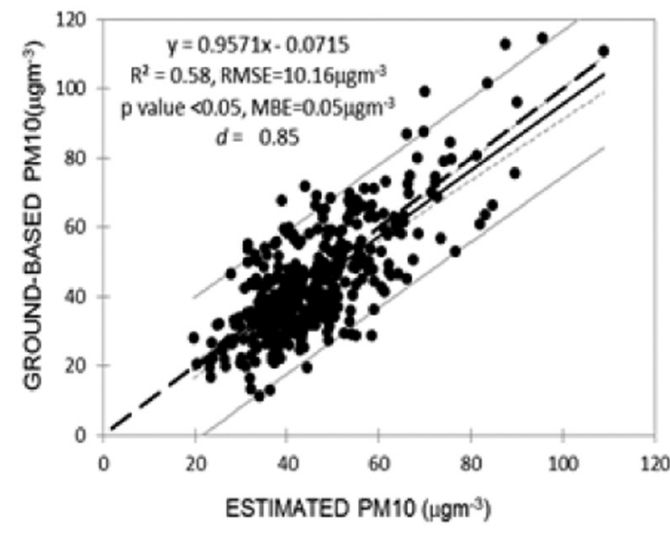

(b)

\begin{tabular}{|c|c|}
\hline ........ Conf. interval (Mean 95\%) & Conf. interval (Obs. 95\%) \\
\hline - linear Modd & - - Linear (perfect line) \\
\hline
\end{tabular}

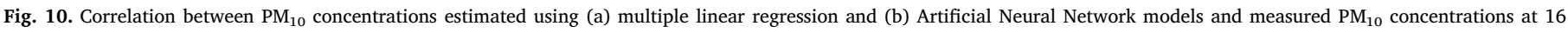
stations over Malaysia during 2007-2011.

interval of the observations, indicating a satisfactory accuracy in predicting the $\mathrm{PM}_{10}$ concentrations from satellite datasets, even over a tropical environment with large satellite data missing and perturbed data due to cloud contamination. Meanwhile, Yap and Hashim (2013) used $\mathrm{PM}_{10}$ concentrations from only 3 stations in Peninsular Malaysia for validation of the estimated monthly $\mathrm{PM}_{10}$ using the mixed effects model (the model was calibrated using data from 31 stations), obtaining an $\mathrm{R}^{2}$ of 0.80 . In our study, we used $\mathrm{PM}_{10}$ measurements from 29 stations for the models training/calibration and another 16 stations for the models validation, resulting in satisfactory $\mathrm{R}^{2}$ values of 0.56 and 0.58 for MLR and ANN models, respectively after the validation procedure (Fig. 10). The validation results give credit to the accuracy of the developed MLR and ANN models for the $\mathrm{PM}_{10}$ estimations over Malaysia. It should be noted that the MLR and ANN models developed based on "training" stations only over the Peninsular Malaysia, resulted in larger errors in the $\mathrm{PM}_{10}$ estimations over the island Malaysia. Therefore, the current selection of stations over both regions and for various atmospheric and meteorological conditions seems to be the most intended way for model development. In a future step, different models will be developed for $\mathrm{PM}_{10}$ and $\mathrm{PM}_{2.5}$ estimations separately over Peninsular Malaysia and Island Malaysia for more detailed predictions.

\subsection{Sensitivity analysis}

The $\mathrm{AOD}_{550}$ uncertainties were described in Section 3.2, but have not been evaluated in the model development or for any other sensitivity study concerning the $\mathrm{PM}_{10}$ uncertainties. This is because the typical errors from the correlations between $\mathrm{AOD}_{550}$ and $\mathrm{PM}_{10}$ are larger than the $\mathrm{AOD}_{550}$ retrieval uncertainties, and the same is true for the other MODIS retrievals. Thus, any sensitivity study will result in $\mathrm{PM}_{10}$ uncertainties lesser than those obtained by the developed models. In this section, a sensitivity analysis was performed by changing the variables $\mathrm{AOD}_{550}, \mathrm{RH}$, surface temperature and $\mathrm{k}$ index as much as $\pm 5 \%$ and $\pm 10 \%$ and the results show that the estimated $\mathrm{PM}_{10}$ concentrations are well within the measurement uncertainties (Table 5). Comparison between the measured and simulated $\mathrm{PM}_{10}$ concentrations over the stations used for the model training showed that the RMSE varies between 10.51 and $10.70 \mu \mathrm{g} \mathrm{m}^{-3}$ for $\mathrm{a} \pm 10 \%$ change in $\mathrm{AOD}_{550}$ or in any other parameter, suggesting negligible changes in simulated $\mathrm{PM}_{10}$ concentrations due to uncertainties in the input variables. It should be noted that negligible differences in the statistical indicators ( $\mathrm{R}^{2}$ and RMSE) for a $\pm 5 \%-10 \%$ change in the input parameters were also observed for the MLR model.

\subsection{Spatial distribution of estimated $P M_{10}$}

The seasonal-mean spatial distributions of the estimated $\mathrm{PM}_{10}$ concentrations over entire Malaysia during 2007-2011 are shown in Fig. $11 \mathrm{a}-\mathrm{d}$ at $10 \times 10 \mathrm{~km}$ spatial resolution, using the ANN model. The seasonal-mean spatial mapping was performed by averaging the daily $\mathrm{PM}_{10}$ concentrations in each season. Very similar seasonal maps have been obtained using the MLR model (not shown).

As expected from the $\mathrm{AOD}_{550}$ spatial distribution, the dry season is associated with high $\mathrm{PM}_{10}$ concentrations reaching about $90-110 \mu \mathrm{g} \mathrm{m}^{-3}$ over the densely-populated southwestern part of the Peninsular Malaysia (Fig. 11a). Even higher $\mathrm{PM}_{10}$ concentrations are revealed over parts in the central Sabah and Sarawak, reaching above $\sim 140 \mu \mathrm{g} \mathrm{m}^{-3}$, due to the influence of severe biomass burning during the dry season. These high $\mathrm{PM}_{10}$ concentrations are also attributed to the extreme haze phenomenon occurred in 2009. According to Hamdan et al. (2010), severe haze conditions covered Sarawak in 2009 (August to early October) due to a strong El Nino event that caused dry weather in the Borneo island and lasted for about 3 months. According to DOE guidelines, $\mathrm{PM}_{10}$ concentrations of about $0-50 \mu \mathrm{g} \mathrm{m}^{-3}$ represent a relatively-clean "background" environment, while values of 51-100, $100-200,200-300$ and $>300 \mu \mathrm{g} \mathrm{m}^{-3}$ correspond to moderate, unhealthy, very unhealthy and hazardous atmospheres, respectively. According to this classification, the atmosphere over the Peninsular Malaysia during the dry season is mostly considered as "moderate", while over many parts of the Island Malaysia the atmospheric conditions are classified as "unhealthy". During the wet season (Fig. 11b), the estimated $\mathrm{PM}_{10}$ are much lower due to rainy washout (Juneng et al., 2009) and only over the urban regions and northernmost areas of the Peninsular Malaysia and Sabah \& Sarawak may reach up to $\sim 90-110 \mu \mathrm{g} \mathrm{m}^{-3}$. In April-May (Fig. 11c), the $\mathrm{PM}_{10}$ spatial distribution exhibits great similarities with that of the wet season, with maximum concentrations over the urban centers and central-south parts of the Island Malaysia due to beginning of forest fires. The main sources of aerosols during this inter-monsoon season are vehicles emissions, industries and open burning activities (Jamil et al., 2011). Finally, October (Fig. 11d) exhibits higher $\mathrm{PM}_{10}$ concentrations over many parts of the Peninsular Malaysia as well as in Sabah and Sarawak resulting in high heterogeneity in the $\mathrm{PM}_{10}$ mapping, similar to that observed during the dry season.

The seasonal-mean measured and estimated $\mathrm{PM}_{10}$ concentrations over the 45 stations during 2007-2011 are shown in Figs. 12-15. During the dry season (Fig. 12), the estimated $\mathrm{PM}_{10}$ concentrations vary widely between the stations from $\sim 30 \mu \mathrm{g} \mathrm{m}^{-3}$ (Bachang and Kapit) to $\sim 60-80 \mu \mathrm{g} \mathrm{m}^{-3}$ over the urban and industrial stations, such as Bukit 
Table 5

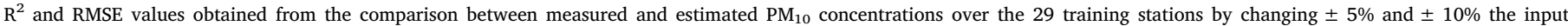
parameters in the ANN model.

\begin{tabular}{|c|c|c|c|c|}
\hline Parameter & AOD & Relative humidity & Surface temperature & $\mathrm{k}$ index \\
\hline Original & $\begin{array}{l}\mathrm{R}^{2}=0.58 \\
\mathrm{RMSE}=10.61 \mu \mathrm{g} \mathrm{m}{ }^{-3}\end{array}$ & $\begin{array}{l}\mathrm{R}^{2}=0.58 \\
\mathrm{RMSE}=10.61 \mu \mathrm{g} \mathrm{m}^{-3}\end{array}$ & $\begin{array}{l}\mathrm{R}^{2}=0.58 \\
\mathrm{RMSE}=10.61 \mu \mathrm{g} \mathrm{m} \mathrm{m}^{-3}\end{array}$ & $\begin{array}{l}\mathrm{R}^{2}=0.58 \\
\mathrm{RMSE}=10.61 \mu \mathrm{g} \mathrm{m}^{-3}\end{array}$ \\
\hline Original parameter minus $5 \%$ & $\begin{array}{l}\mathrm{R}^{2}=0.56 \\
\mathrm{RMSE}=10.68 \mu \mathrm{g} \mathrm{m}^{-3}\end{array}$ & $\begin{array}{l}\mathrm{R}^{2}=0.56 \\
\mathrm{RMSE}=10.65 \mu \mathrm{g} \mathrm{m}^{-3}\end{array}$ & $\begin{array}{l}\mathrm{R}^{2}=0.56 \\
\mathrm{RMSE}=10.66 \mu \mathrm{g} \mathrm{m}^{-3}\end{array}$ & $\begin{array}{l}\mathrm{R}^{2}=0.55 \\
\mathrm{RMSE}=10.60 \mu \mathrm{g} \mathrm{m}^{-3}\end{array}$ \\
\hline Original parameter plus $5 \%$ & $\begin{array}{l}\mathrm{R}^{2}=0.57 \\
\mathrm{RMSE}=10.65 \mu \mathrm{g} \mathrm{m}^{-3}\end{array}$ & $\begin{array}{l}\mathrm{R}^{2}=0.57 \\
\mathrm{RMSE}=10.61 \mu \mathrm{g} \mathrm{m}^{-3}\end{array}$ & $\begin{array}{l}\mathrm{R}^{2}=0.56 \\
\mathrm{RMSE}=10.68 \mu \mathrm{g} \mathrm{m}^{-3}\end{array}$ & $\begin{array}{l}\mathrm{R}^{2}=0.56 \\
\mathrm{RMSE}=10.64 \mu \mathrm{g} \mathrm{m}^{-3}\end{array}$ \\
\hline Original parameter minus $10 \%$ & $\begin{array}{l}\mathrm{R}^{2}=0.54 \\
\mathrm{RMSE}=10.70 \mu \mathrm{g} \mathrm{m}^{-3}\end{array}$ & $\begin{array}{l}\mathrm{R}^{2}=0.57 \\
\mathrm{RMSE}=10.61 \mu \mathrm{g} \mathrm{m}^{-3}\end{array}$ & $\begin{array}{l}\mathrm{R}^{2}=0.56 \\
\mathrm{RMSE}=10.63 \mu \mathrm{g} \mathrm{m} \mathrm{m}^{-3}\end{array}$ & $\begin{array}{l}\mathrm{R}^{2}=0.56 \\
\mathrm{RMSE}=10.67 \mu \mathrm{g} \mathrm{m}^{-3}\end{array}$ \\
\hline Original parameter plus $10 \%$ & $\begin{array}{l}\mathrm{R}^{2}=0.58 \\
\mathrm{RMSE}=10.51 \mu \mathrm{g} \mathrm{m}^{-3}\end{array}$ & $\begin{array}{l}\mathrm{R}^{2}=0.56 \\
\mathrm{RMSE}=10.56 \mu \mathrm{g} \mathrm{m}^{-3}\end{array}$ & $\begin{array}{l}\mathrm{R}^{2}=0.56 \\
\mathrm{RMSE}=10.70 \mu \mathrm{g} \mathrm{m}^{-3}\end{array}$ & $\begin{array}{l}\mathrm{R}^{2}=0.56 \\
\mathrm{RMSE}=10.70 \mathrm{\mu g} \mathrm{m}^{-3}\end{array}$ \\
\hline
\end{tabular}
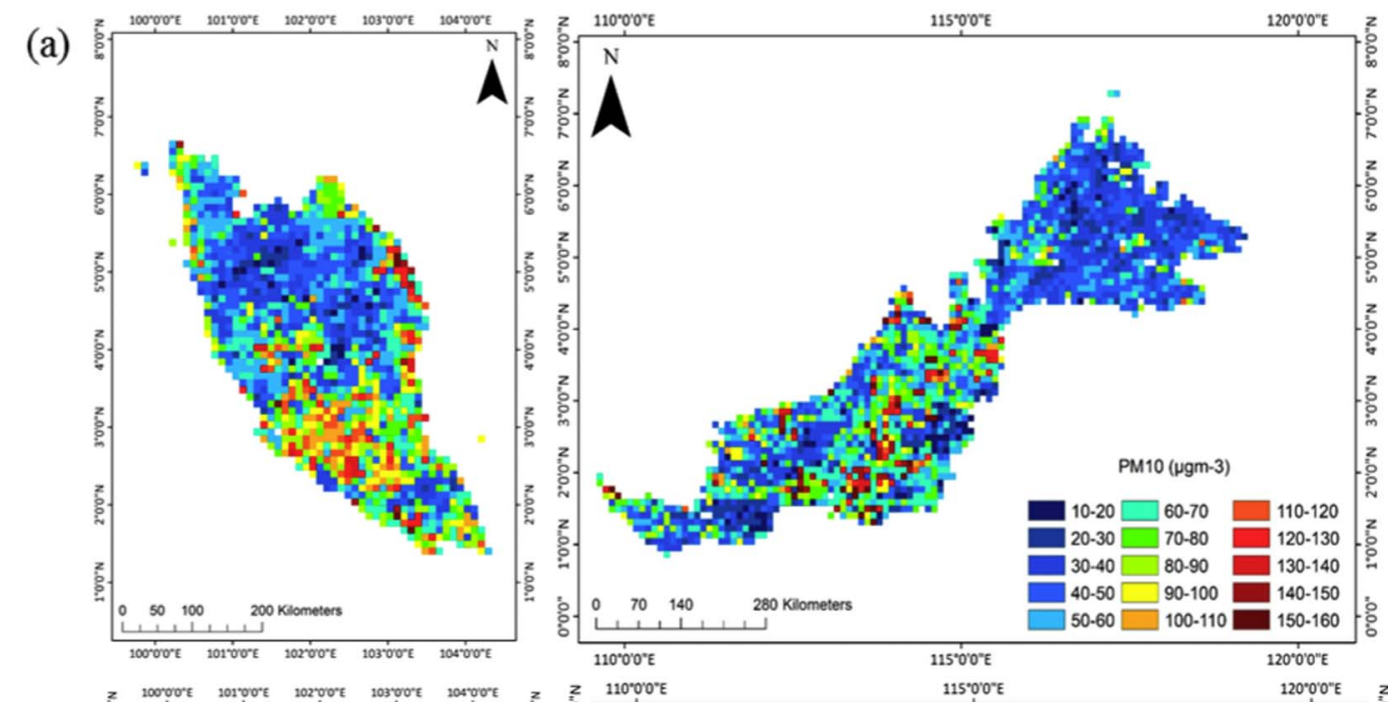

(b)
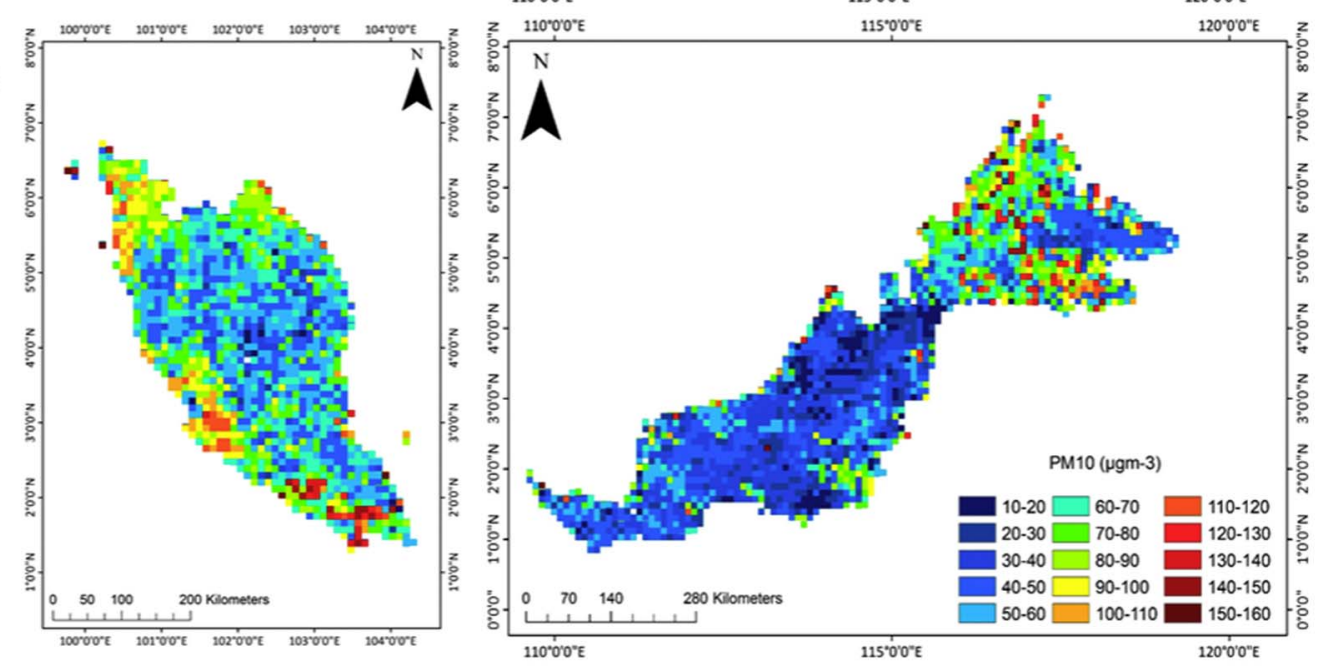

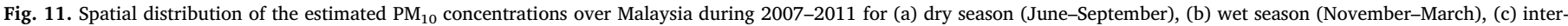
monsoon (April-May) and, (d) inter-monsoon (October).

Rambai $\left(58.4 \pm 8.1 \mu \mathrm{g} \mathrm{m}^{-3}\right)$, Petaling Jaya $\left(95.7 \pm 18.4 \mu \mathrm{g} \mathrm{m}^{-3}\right)$, Shah Alam $\left(71.7 \pm 22.7 \mu \mathrm{g} \mathrm{m}^{-3}\right)$, Balok $\left(72.9 \pm 27.7 \mu \mathrm{g} \mathrm{m}^{-3}\right)$, Klang $\left(76.0 \pm 10.1 \mu \mathrm{g} \mathrm{m}^{-3}\right)$ and Tawau $\left(81.7 \pm 11.4 \mu \mathrm{g} \mathrm{m}^{-3}\right)$. According to Mahmud and Iza (2010), Bukit Rambai experiences high airpollution levels throughout the year, since it is located in an industrial area with high anthropogenic and industrial emission rates and is also strongly effected by seasonal haze transported from neighboring countries. The seasonal-mean measured and estimated $\mathrm{PM}_{10}$ values maximize over the urban and industrial sites, while great consistency is revealed between measured and estimated $\mathrm{PM}_{10}$ between the sites.

During the wet season (Fig. 13), the $\mathrm{PM}_{10}$ concentrations decrease and the most of the stations located along the east coast of the Peninsular Malaysia, like Kota Bharu, Tanah Merah and Kuantan exhibit the lowest $\mathrm{PM}_{10}$ concentrations (in the order of $30-40 \mu \mathrm{g} \mathrm{m}^{-3}$ ) as a result of rainy washout (Juneng et al., 2009). In contrast, industrial stations like Klang, Putrajaya, Balok, Seremban, Shah Alam, Paka-Kertih, Kemaman and Petaling Jaya are the most $\mathrm{PM}_{10}$-loaded with concentrations of about $50-80 \mu \mathrm{g} \mathrm{m}^{-3}$ due to the continuous emissions in the industrial zones.

The $\mathrm{PM}_{10}$ concentrations during the inter-monsoon (April-May) season show a smaller variation between the stations with values generally ranging between 40 and $60 \mu \mathrm{g} \mathrm{m}^{-3}$ (Fig. 14). Stations like 
(c)
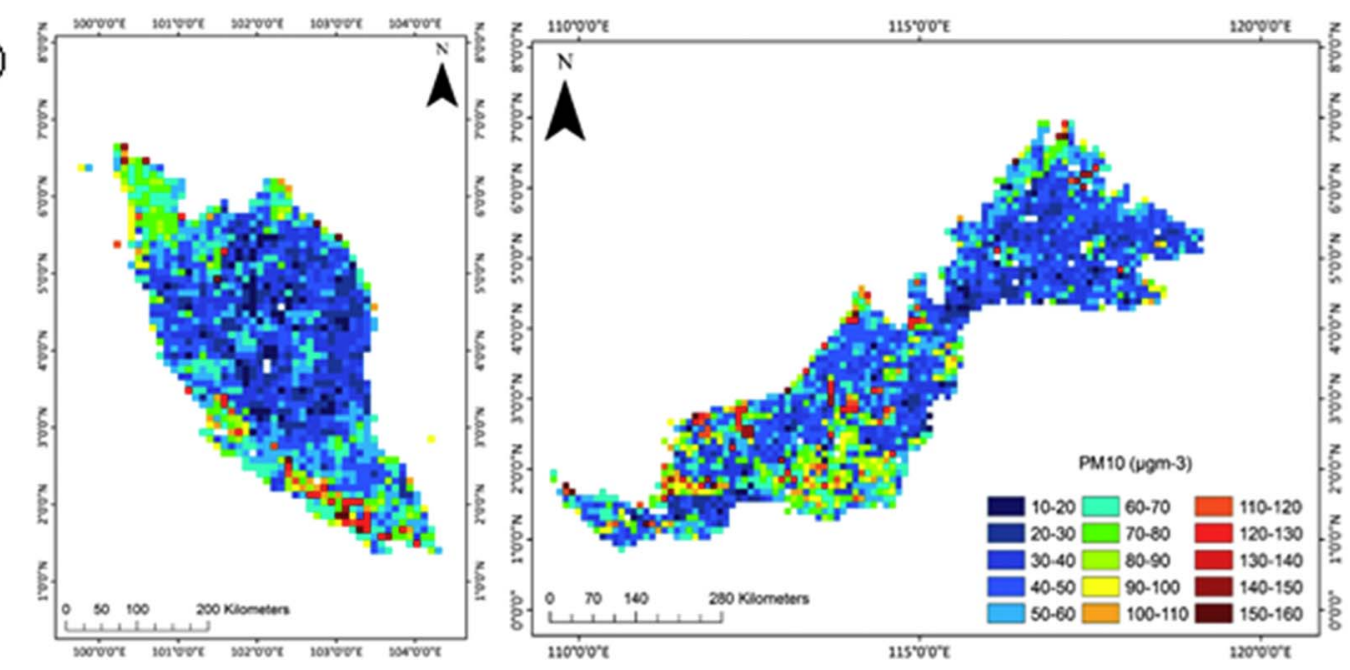

(d)

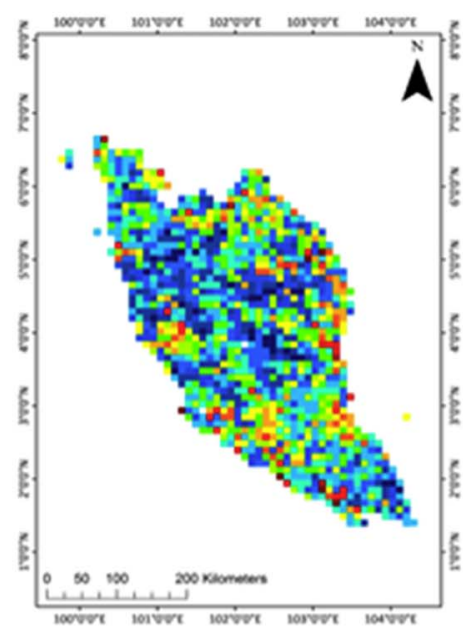

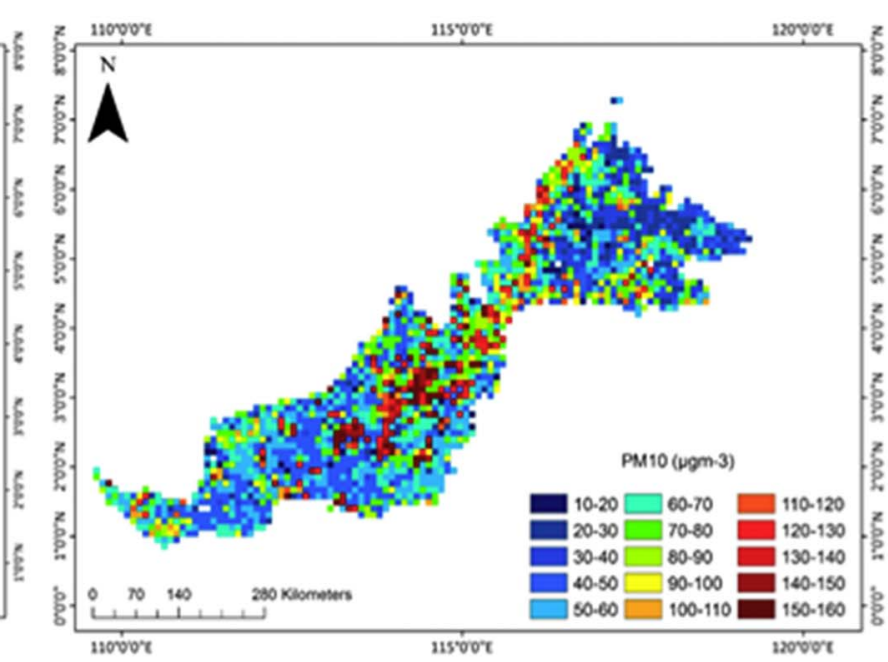

Fig. 11. (continued)
Nilai and Johor Bahru exhibit the highest $\mathrm{PM}_{10}$ concentrations ranging between 65 and $85 \mu \mathrm{g} \mathrm{m}^{-3}$ while rural areas show the lowest $\mathrm{PM}_{10}$ concentrations which is $<60 \mu \mathrm{g} \mathrm{m}^{-3}$. The $\mathrm{PM}_{10}$ concentrations during October (Fig. 15) exhibit a similar pattern to that observed during April-May but with higher values, which are usually above $40 \mu \mathrm{g} \mathrm{m}^{-3}$ except for Jerantut, Kangar, Labuan, Pegoh, Sandakan, Kuala Selangor, Limbang, Sri Aman and Tanah Merah. Some stations exhibit very high monthly $\mathrm{PM}_{10}$ concentrations reaching $100 \mu \mathrm{g} \mathrm{m}^{-3}$, like Shah Alam $\left(144.7 \pm 25.4 \mu \mathrm{g} \mathrm{m}^{-3}\right)$, Tasek $\left(122.23 \pm 25.4 \mu \mathrm{g} \mathrm{m}^{-3}\right)$ and Tawau $\left(98.6 \pm 22.7 \mu \mathrm{g} \mathrm{m}^{-3}\right)$.

During non-haze episodes, air pollution over Malaysia is mostly due to motor-vehicle emissions, industry and biofuel burning (Afroz et al., 2003; Jamil et al., 2011), thus favoring the accumulation of aerosols around the urban and industrialized areas. Many other factors that are not included in the current models, like the spatio-temporal distribution of rainfall, seasonally-changed winds and influence of the El-Nino

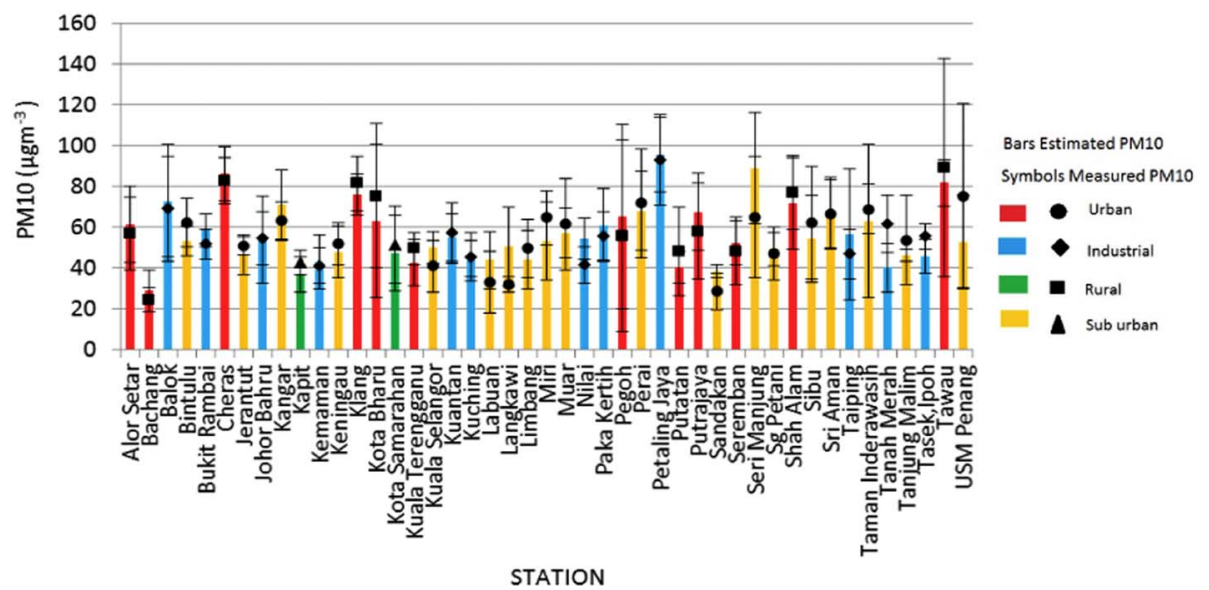

Fig. 12. Seasonal-mean measured and estimated $\mathrm{PM}_{10}$ concentrations at the 45 stations in Malaysia during the dry season. 


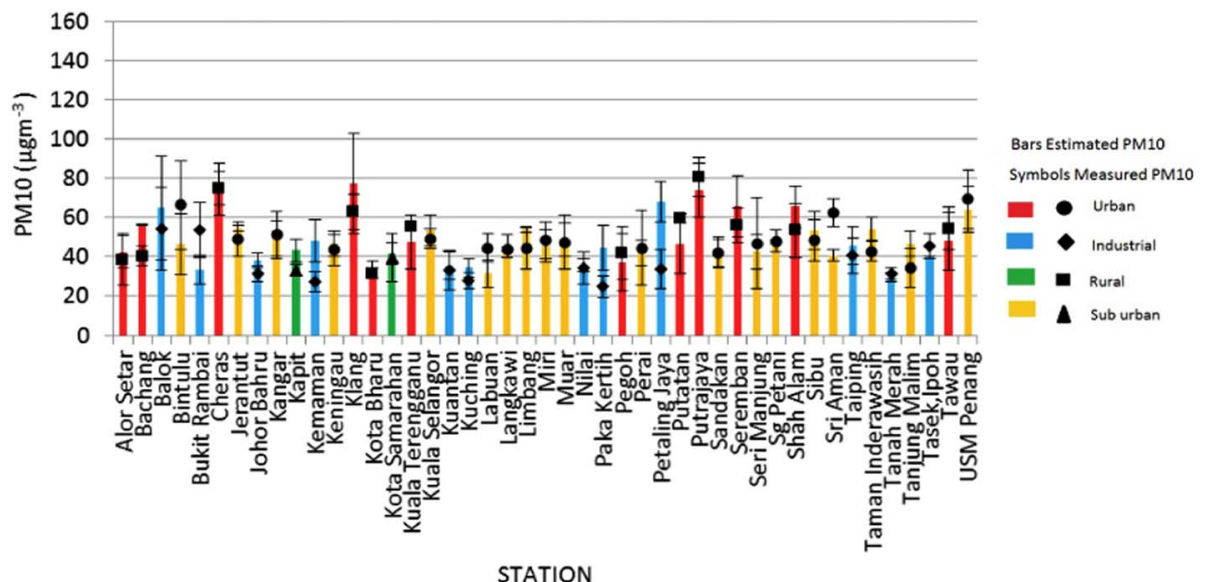

Fig. 13. Same as in Fig. 12, but for the wet season.

Southern Oscillation strongly affect the atmospheric dynamics (e.g. drought, boundary-layer height, dilution processes, transported aerosol plumes, rainy washout) and, in turn, the aerosol loading and $\mathrm{PM}_{10}$ concentrations over Malaysia. Despite all these challenges, the large gaps in the satellite dataset due to extensive cloud cover and the large heterogeneity in the aerosol field, the current analysis shows that $\mathrm{PM}_{10}$ monitoring from space over Malaysia can be achieved with high accuracy (via both MLR and ANN techniques), which allows future $\mathrm{PM}_{10}$ forecasts of good quality for monitoring local and regional air pollution on daily basis. The techniques developed in this study for $\mathrm{PM}_{10}$ estimations will be helpful to assess the pollution levels over Malaysia at large spatial scales, which is essential for developing the Malaysian Environmental Performance Index (EPI). Currently, the global EPI is computed via $\mathrm{PM}_{2.5}$ estimations using MODIS AOD at 10-km spatial resolution (Van Donkelaar. et al., 2010). This index needs to be refined in order to represent the local variations, so global EPI can adopt local values in its calculations. Once $\mathrm{PM}_{2.5}$ data becomes available in long-term basis over Malaysia, similar to the current techniques and models may be developed to predict $\mathrm{PM}_{2.5}$ concentrations and distribution over the country.

\section{Conclusions}

The current study dealt with $\mathrm{PM}_{10}$ estimations from space and mapping of the seasonal-mean $\mathrm{PM}_{10}$ concentrations $(10 \times 10 \mathrm{~km}$ spatial resolution) over Malaysia during the period 2007-2011. Multiple Terra-MODIS retrievals like $\mathrm{AOD}_{550}$, atmospheric profiles and calibrated radiances were used for computations of the spatial distributions of aerosol, $\mathrm{RH}$, surface temperature and stability index that were involved in the developed MLR and ANN models for the $\mathrm{PM}_{10}$ estimations from space. The estimated RH showed the potential of remote-sensing data to provide atmospheric parameters needed to run the model due to strong correlation and low bias against ground-based measurements $\left(\mathrm{R}^{2}=0.78, \mathrm{RMSE}=5.14 \%\right.$ and $\left.\mathrm{MBE}=-0.06 \%\right)$. Furthermore, the surface temperature calculated using MODIS data revealed moderate-to-good correlation with the ambient temperature from the meteorological stations $\left(\mathrm{R}^{2}=0.49\right.$, RMSE $=2.68^{\circ} \mathrm{C}$ and MBE $=-0.03^{\circ} \mathrm{C}$ ). Multiple linear regression (MLR) and Artificial Neural Network (ANN) models were developed using the MODIS $\mathrm{AOD}_{550}$, atmospheric stability, $\mathrm{RH}$ and surface temperature as variables for better estimations of $\mathrm{PM}_{10}$, instead of the simple linear regression between measured $\mathrm{PM}_{10}$ concentrations and satellite AODs. Stepwise regression techniques examined the performance of each parameter in $\mathrm{PM}_{10}$ estimates and the MODIS AOD 550 was found to yield the highest correlation with $\mathrm{PM}_{10}\left(\mathrm{R}^{2}=0.59\right)$, followed by atmospheric stability $\left(\mathrm{R}^{2}=0.16\right)$ and surface temperature $\left(\mathrm{R}^{2}=0.11\right)$. The inclusion of all parameters in the MLR model increased the accuracy of the predicted $\mathrm{PM}_{10}\left(\mathrm{R}^{2}=0.66\right)$. In future research, both wind speed and wind direction will be included in the MLR and ANN models attaining for more accurate estimations of the $\mathrm{PM}_{10}$ concentrations, since the wind regime controls the air-mass trajectories, thus affecting the $\mathrm{PM}_{10}$. The MLR and ANN models developed for $\mathrm{PM}_{10}$ estimation from space were initially trained against measured $\mathrm{PM}_{10}$ concentrations at 29 stations homogeneously distributed over Malaysia resulting in average RMSE values of $12.39 \mu \mathrm{g} \mathrm{m}^{-3}$ and $11.61 \mu \mathrm{g} \mathrm{m}^{-3}$, respectively indicating satisfactory accuracy in the estimates. The ANN model resulted in slightly higher accuracy compared to MLR and an RMSE of $10.16 \mu \mathrm{g} \mathrm{m}^{-3}$ was found after model's validation against $\mathrm{PM}_{10}$ measurements at 16 stations. The seasonal-mean $\mathrm{PM}_{10}$ mapping over Malaysia revealed significant spatio-temporal heterogeneities in the

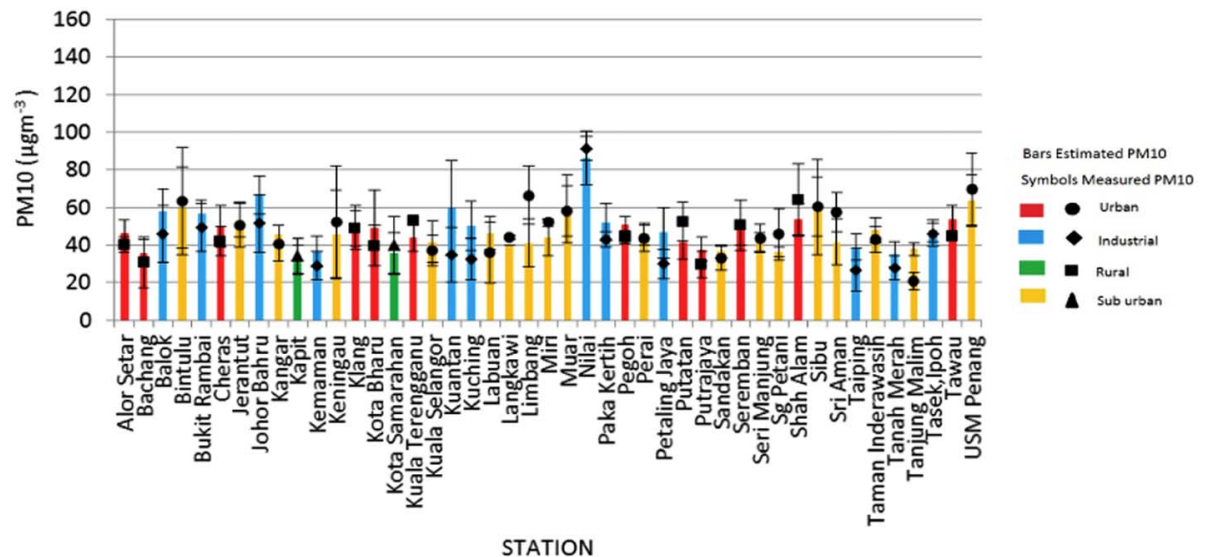

Fig. 14. Same as in Fig. 12, but for the inter-monsoon (April-May) season. 


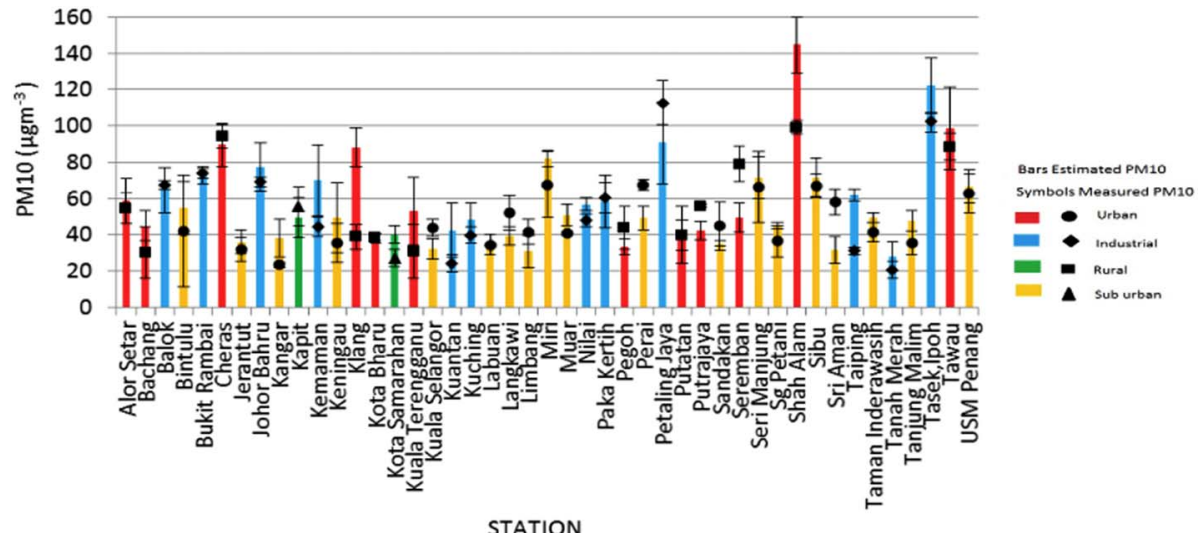

Fig. 15. Same as in Fig. 12, but for the inter-monsoon (October) season.

$\mathrm{PM}_{10}$ concentrations, as a result of the high heterogeneous aerosol and meteorology fields. The high performance of the MLR and ANN models for $\mathrm{PM}_{10}$ estimations over Malaysia allows for future estimates of $\mathrm{PM}_{2.5}$ concentrations from space and monitoring of the Environmental Performance Index by developing separate models over the Peninsular and Island Malaysia. When more daily data pairs (AOD and PM) become available over Malaysia we will use the mixed-effects model combined with meteorological parameters for PM estimations on a daily basis.

\section{Acknowledgements}

This study is financially supported by the Ministry of Higher Education Malaysia under the Fundamental Research Grant Scheme (vote no: R.J130000.7827.4F669). The authors are thankful to the Department of Environment (DOE) and Dr. Mohd Nadzri Md Reba for providing the $\mathrm{PM}_{10}$ concentrations data. Authors also acknowledge NASA for making MODIS data available to users.

\section{References}

Abas, M.R.B., Oros, D.R., Simoneit, B.R.T., 2004. Biomass burning as the main source of organic aerosol particulate matter in Malaysia during haze episodes. Chemosphere $55,1089-1095$.

Abdullah, N.A., Shuhaimi, S.H., Toh., Y.Y., Shapee., A.H., Mohamad, M., 2011. The Study of Seasonal Variation of $\mathrm{PM}_{10}$ Concentration in Peninsular, Sabah and Sarawak. Malaysian Meteorological Department (Research publication No 9/2011. ISBN 978967-5676-20-8).

Afroz, R., Hassan, M., Ibrahim, N.K., 2003. Review of air pollution and health impacts in Malaysia. Environ. Res. 92, 71-77.

Alias, A.N., Mat Jafri, M.Z., Lim, H.S., Saleh, N.M., Chumiran, S.H., Mohamad, A., 2014. Aerosol characterization over Penang, Malaysia using aerosol robotic network (AERONET). Appl. Mech. Mater. 661, 81-92.

Awang, M.B., Jaafar, A.B., Abdullah, A.M., Ismail, M.B., Hassan, M.N., Abdullah, R., Johan, S., Noor, H., 2000. Air quality in Malaysia: impacts, management issues and future challenges. Respirology 5, 183-196.

Balakrishnan, K., Sankar, S., Parikh, J., Padmavathi, R., Srividya, K., Venugopal, V., 2002. Daily average exposures to respirable particulate matter from combustion of biomass fuels in rural households of Southern India. Environ. Health Perspect. 110 (11), 1069-1075.

Ballester, F., Estarlich, M., Iniguez, C., Llop, S., Ramon, R., Esplugues, A., Lacasana, M., Rebagliato, M., 2010. Air Pollution Exposure During Pregnancy and Reduced Birth Size: A Prospective Birth Cohort Study in Valencia. Environmental Health, Spain.

Barmpadimos, I., Hueglin, C., Keller, J., Henne, S., Prévôt, A.S.H., 2011. Influence of meteorology on $\mathrm{PM}_{10}$ trends and variability in Switzerland from 1991 to 2008 . Atmos. Chem. Phys. 11 (4), 1813-1835.

Beloconi, A., Kamarianakis, Y., Chrysoulakis, N., 2016. Estimating urban $\mathrm{PM}_{10}$ and $\mathrm{PM}_{2.5}$ concentrations, based on synergistic MERIS/AATSR aerosol observations, land cover and morphology data. Remote Sens. Environ. 172, 148-164.

Benas, N., Beloconi, A., Chrysoulakis, N., 2013. Estimation of urban $\mathrm{PM}_{10}$ concentration, based on MODIS and MERIS/AATSR synergistic observations. Atmos. Environ. 79, 448.

Campbell, J.R., Reid, J.S., Westphal, D.L., Zhang, J., Tackett, J.L., Chew, B.N., Welton, E.J., Shimizu, A., Sugimoto, N., Aoki, K., Winker, D.M., 2013. Characterizing the vertical profile of aerosol particle extinction and linear depolarization over Southeast Asia and the Maritime Continent: the 2007-2009 view from CALIOP. Atmos. Res. $122,520-543$

Chitranshi, S., Sharma, S.P., Dey, S., 2014. Satellite-based estimates of outdoor particulate pollution $\left(\mathrm{PM}_{10}\right)$ for Agra City in northern India. Air Qual. Atmos. Health, vol. 8 (issue1), 55-56.

Chubarova, N., Nezval, Y., Sviridenkov, I., Smirnov, A., Slutsker, I., 2012. Smoke aerosol and its radiative effects during extreme fire event over central Russia in summer 2010. Atmos. Meas. Tech. 5, 557-568.

Dey, S., Di Girolamo, L., van Donkelaar, A., Tripathi, S.N., Gupta, T., Mohan, M., 2012. Variability of outdoor fine particulate $\left(\mathrm{PM}_{2.5}\right)$ concentration in the Indian Subcontinent: a remote sensing approach. Remote Sens. Environ. 127, 153-161.

Dominici, F., Peng, R.D., Bell, M.L., Pham, L., McDermontt, A., Zeger, S.L., Samet, J.M., 2006. Fine particulate air pollution and hospital admission for cardiovascular and respiratory diseases. The Journal of the America Medical Association 295 (10), 1127-1134.

Dominick, D., Juahir, H., Latif, M.T., Zain, S.M., Aris, A.Z., 2012. Spatial assessment of air quality patterns in Malaysia using multivariate analysis. Atmos. Environ. 60, $172-181$.

Dumka, U.C., Kaskaoutis, D.G., Srivastava, M.K., Devara, P.C.S., 2015. Scattering and absorption properties of near-surface aerosol over Gangetic-Himalayan region: the role of boundary layer dynamics and long-range transport. Atmos. Chem. Phys. 15, 1555-1572.

Eck, T.F., Holben, B.N., Ward, D.E., Mukelabai, M.M., Dubovik, O., Smirnov, A., Schafer, J.S., Hsu, N.C., Piketh, S.J., Queface, A., Le Roux, J., Swap, R.J., Slutsker, I., 2003. Variability of biomass burning aerosol optical characteristics in southern Africa during the SAFARI 2000 dry season campaign and a comparison of single scattering albedo estimates from radiometric measurements. J. Geophys. Res. 108 (D13), 8477. http://dx.doi.org/10.1029/2002JD002321.

Elossta, E., Qahwaji, R., Ipson, S.S., 2013. Detection of dust storms using MODIS reflective and emissive bands. IEEE J-STARS 6, 2480-2485.

Emili, E., Popp, C., Pettita, M., Riffler, M., Wunderle, S., Zebisch, M., 2010. PM 10 remote sensing from geostationary SEVIRI and polar-orbiting MODIS sensors over the complex terrain of the European Alpine region. Remote Sens. Environ. 114, 11.

Engel-Cox, J.A., Hoff, R.M., Haymet, A.D.J., 2004. Recommendations on the use of satellite remote-sensing data for urban air quality. J. Air Waste Manage. Assoc. 54 (11), 1360-1371.

EPI (Environmental Performance Index), 2016. Environmental Performance Index - 2016 Report. http://epi.yale.edu/country/malaysia.

Gao, B.C., Kaufman, Y.J., 2003. Water vapor retrievals using Moderate Resolution Imaging Spectroradiometer (MODIS) near-infrared channels. J. Geophys. Res. 108 (doi:10.1029/2002JD003023. issn; 0148-0227).

Gupta, P., Christopher, S.A., 2008. Seven year particulate matter air quality assessment from surface and satellite measurements. Atmos. Chem. Phys. 8, 3311-3324. http:// dx.doi.org/10.5194/acp-8-3311-2008.

Gupta, P., Christopher, S.A., 2009a. Particulate matter air quality assessment using integrated surface, satellite, and meteorological products: multiple regression approach. J. Geophys.Res.-Atmos. 114, D14205. http://dx.doi.org/10.1029/ 2008JD011496.

Gupta, P., Christopher, S.A., 2009. Particulate matter air quality assessment using integrated surface, satellite, and meteorological products: 2 . A neural network approach. J. Geophys. Res. -Atmos. 114 (D20205), 1-14. http://dx.doi.org/10.1029/ 2008JD011497.

Gupta, P., Christopher, S.A., Wang, J., Gehrig, R., Lee, Y., Kumar, N., 2006. Satellite remote sensing of particulate matter and air quality assessment over global cities. Atmos. Environ. 40, 5880-5892.

Ha Trang, N., Tripathi, N.K., 2014. Spatial correlation analysis between particulate matter $10\left(\mathrm{PM}_{10}\right)$ hazard and respiratory diseases in Chiang Mai Province, Thailand. Int. Arch. Photogramm. Remote. Sens. Spat. Inf. Sci. XL-8, 185-191. http://dx.doi.org/ 10.5194/isprsarchives-XL-8-185-2014. http://dx.doi.org/10.1029/2007JD009661. 
Ham, F.M., Kostanic, I., 2001. Principles of Neurocomputing for Science and Engineering. 478 McGraw Hill, New York.

Hamdan, H., Zakaria, R., Lias, N., Taat, A., Mat Adam., S.F., 2010. Malaysian Meteorological Department: Extreme Weather of Sarawak 2009. Ministry of Science, Technology and Innovation (MOSTI).

Han, H.-J., Sohn, B.J., 2013. Retrieving Asian dust AOT and height from hyperspectral sounder measurements: an artificial neural network approach. J. Geophys. Res. 118, $837-845$.

Hoff, R.M., Christopher, S.A., 2009. Remote sensing of particulate pollution from space: have we reached the Promised Land? J. Air Waste Manage. Assoc. 59, 645-675.

Hu, X., Waller, L.A., Lyapustin, A., Wang, Y., et al., 2014. Estimating ground-level $\mathrm{PM}_{2.5}$ concentrations in the Southeastern United States using MAIAC AOD retrievals and a two-stage model. Remote Sens. Environ. 140, 220-232.

Hyer, E.J., Reid, J.S., Prins, E.M., Hoffman, J.P., Schmidt, C.C., Miettinen, J.I., Giglio, L., 2013. Patterns of fire activity over Indonesia and Malaysia from polar and geostationary satellite observations. Atmos. Res. 122, 504-519.

Ichoku, C., Chu, D.A., Mattoo, S., Kaufman, Y.J., Remer, L.A., Tanr'e, D., Slutsker, I., Holben, B.N., 2002. A spatio-temporal approach for global validation and analysis of MODIS aerosol products. Geophys. Res.Lett. 29, 8006. http://dx.doi.org/10.1029/ 2001GL013206.

Jamil, A., Makmom, A.A., Saeid, P., Firuz, R.M., Prinaz, R., 2011. PM $\mathrm{PM}_{10}$ monitoring using MODIS AOT and GIS, Kuala Lumpur, Malaysia. Res J.Chem Envron., vol. 15.

Juneng, L., Latif, M.T., Tangang, F.T., Mansor, H., 2009. Spatio-temporal characteristics of $\mathrm{PM}_{10}$ concentration across Malaysia. Atmos. Environ. 43, 4584-4594.

Kambezidis, H.D., Kaskaoutis, D.G., 2008. Aerosol climatology over four AERONET sites: an overview. Atmos. Environ. 42, 1892-1906.

Kanniah, K.D., Lim, H.Q., Kaskaoutis, D.G., Cracknell, A.P., 2014a. Investigating aerosol properties in Peninsular Malaysia via the synergy of satellite remote sensing and ground-based measurements. Atmos. Res. 138 (1), 223-239.

Kanniah, K.D., Kamarul Zaman, N.A.F., Lim, H.Q., Md Reba, M.N., 2014b. In: Comerón, Adolfo (Ed.), Monitoring Particulate Matters in Urban Areas in Malaysia Using Remote Sensing and Ground Based Measurements, Remote Sensing of Clouds and the Atmosphere XIX; and Optics in Atmospheric Propagation and Adaptive Systems XVII,

Kanniah, K.D., Kaskaoutis, D.G., San Lim, H., Latif, M.T., Zaman, N.A.F.K., Liew, J., 2016. Overview of atmospheric aerosol studies in Malaysia: known and unknown. Atmos. Res. 182, 302-318.

Kaskaoutis, D.G.N., Sifakis, A. Retalis, Kambezidis, H.D., 2010. Aerosol monitoring over Athens using satellite and ground-based measurements. Adv. Meteorol., vol. 2010 (Article ID 147910, doi:10.1155/2010/147910).

Kaskaoutis, D.G., Kumar, S., Sharma, D., Singh, R.P., Kharol, S.K., Sharma, M., Singh, A.K., Singh, S., Singh, A., Singh., D., 2014. Effects of crop residue burning on aerosol properties, plume characteristics and long-range transport over northern India. J. Geophys. Res. 119, 5424-5444. http://dx.doi.org/10.1002/2013JD021357.

Kensten, Y., Brand, A., Fournier., M., Goudreau., S., Kosatsky., T., Maloley., M., Smargiassi, 2011. A: modeling the variation of land surface temperature as determinant of risk of heat-related health events. Int. J. Health Geogr. 10, 7. http:// dx.doi.org/10.1186/1476-072X-10-7.

Khan, M.F., Latif, M.T., Saw, W.H., Amil, N., 2016a. Fine particulate matter associated with monsoonal effect and the responses of biomass fire hotspots in the tropical environment. Atmos. Chem. Phys. 16, 597-617.

Khan, M.F., Sulong, N.A., Latif, M.T., Nadzir, M.S.M., Amil, N., Hussain, D.F.M., Lee, V., Hosaini, P.N., Shaharom, S., Yusoff, N.A.Y.M., Hoque, H.M.S., Chung, J.X., Sahani, M., Tahir, N.M., Juneng, L., Maulud, K.N.A., Abdullah, S.M.S., Fujii, Y., Tohno, S., Mizohata, A., 2016b. Comprehensive assessment of $\mathrm{PM}_{2.5}$ physicochemical properties during the Southeast Asia dry season (southwest monsoon). J. Geophys. Res. Atmos. $121,14,589-14,611$.

Kloog, I., Nordio, F., Coull, B.A., Schwartz, J., 2012. Incorporating local land use regression and satellite aerosol optical depth in a hybrid model of spatiotemporal $\mathrm{PM}_{2.5}$ exposures in the Mid-Atlantic states. Environ. Sci. Technol. 46 (21) 09/2012 http://dx.doi.org/10.1021/es302673e.

Lawrence, M.G., Lelieveld, J., 2010. Atmospheric pollutant outflow from southern Asia: a review. Atmos. Chem. Phys. 10, 11,017-11,096.

Lee, H.J., Liu, Y., Coull, B.A., Schwartz, J., Koutrakis, P., 2011. A novel calibration approach of MODIS AOD data to predict $\mathrm{PM}_{2.5}$ concentrations. Atmospheric Chemistry. Physic. 11, 7991-8002. http://dx.doi.org/10.5194/acp-11-7991-2011.

Levy, R.C., Remer, L.A., Kleidman, R.G., Mattoo, S., Ichoku, C., Kahn, R., Eck, T.F., 2010. Global evaluation of the Collection 5 MODIS dark-target aerosol products over land. Atmos. Chem. Phys. 10, 10399-10420. http://dx.doi.org/10.5194/acp-10-10399 2010.

Levy, R.C., Mattoo, S., Munchak, L.A., Remer, L.A., Sayer, A.M., Patadia, F., Hsu, N.C., 2013. The Collection 6 MODIS aerosol products over land and ocean. Atmos. Meas. Tech. 6, 2989-3034. http://dx.doi.org/10.5194/amt-6-2989-2013.

Liu, Y., Sarnat, J.A., Kilaru, V., Jacob, D.J., Koutrakis, P., 2005. Estimating ground level $\mathrm{PM}_{2.5}$ in the eastern United States using satellite remote sensing. Environ. Sci. Technol. 39 (9), 3269-3278.

Liu, Y., Franklin, M., Kahn, R., Koutrakis, P., 2007. Using aerosol optical thickness to predict ground-level $\mathrm{PM}_{2.5}$ concentrations in the St. Louis area: a comparison between MISR and MODIS. Remote Sens. Environ. 107, 33-44. http://dx.doi.org/10 1016/j.rse.2006.05.022

Mahmud, M., Iza, H.A.L., 2010. Pencemaran udara di Bukit Rambai, Melaka sewaktu peristiwa jerebu tahun 2005 (Air pollution at Bukit Rambai, Melaka during the haze episode of 2005), Geografia. Malaysian Journal of Society and Space (GMJSS) 6, 30-39.

Malm, W.C., Day, D.E., Kreidenweis, S.M., 2000. Light scattering characteristics of aerosols as a function of relative humidity: part I-a comparison of measured scattering and aerosol concentrations using the theoretical models. J. Air Waste Manage. Assoc. 50, 686-700.

Md.Yusof, N.F.F., Ramli, N.A., Yahaya, A.S., Samsuddin, N.A., al Madhoun, W., 2010. Monsoon differences and probability distribution of $\mathrm{PM}_{10}$ concentration. Environ. Monit. Assess. 163 (163(1)), 655-667.

Met One Instruments, Inc., 2013. BAM-1020 Continuous Particulate Monitor. www. metone.com.

Munchak, L., Levy, R., Mattoo, S., Remer, L., Holben, B., Schafer, J., Hostetler, C., Ferrare, R., 2014. MODIS $3 \mathrm{~km}$ aerosol product: applications over land in an urban/suburban region. Atmos Meas Tech. 6 (7), 1747-1759.

Nadzri, O., Mat Jafri, M.Z., Lim, H.S., 2010. Estimating particulate matter concentration over arid region using satellite remote sensing: a case study in Makah, Saudi Arabia. Mod. Appl. Sci., vol. 4 (11).

NASA, 2015. The MODIS Atmosphere Website: http://modisatmos.gsfc.nasa.gov/ MOD07_L2/index.html. (Accessed 10 November 2015).

Nguyen, N.H., Tran, V.A., 2014. Estimation of $\mathrm{PM}_{10}$ From AOT of Satellite Landsat 8 Image Over Hanoi City. International Symposium on Geoinformatics for Spatial Infrastructure Development in Earth and Allied Sciences .

Nordio, F., Kloog, I., Coull, B.A., Chudnovsky, A., et al., 2013. Estimating spatio-temporal resolved $\mathrm{PM}_{10}$ aerosol mass concentrations using MODIS satellite data and land use regression over Lombardy, Italy. Atmos. Environ. 74, 227-236.

North, P., Grey, W., Heckel, A., Fischer, J., Preusker, R., Brockmann, C., 2009. MERIS/ AATSR synergy algorithms for cloud screening, aerosol retrieval, and atmospheric correction. Algorithm Theoretical Basis Document Land Aerosol and Surface Reflectance ATBD. no 21090, 1-44.

Peng, G., Li, J., Chen, Y., Norizan, A.P., Tay, L., 2006. High-resolution surface relative humidity computation using MODIS image in Peninsular Malaysia. Chin. Geogr. Sci. $16,260-264$

Pope, C.A., Brook, R.D., Burnett, R.T., Dockery, D.W., 2011a. How is cardiovascular disease mortality risk affected by duration and intensity of fine particulate matter exposure? An integration of the epidemiologic evidence. Air Qual. Atmos. Health 4 , $5-14$.

Pope III, C.A., Burnett, R.T., Turner, M.C., Cohen, A., Krewski, D., Jerrett, M., Gapstur, S.M., Thun, M.J., 2011b. Lung cancer and cardiovascular disease mortality associated with particulate matter exposure from ambient air pollution and cigarette smoke: shape of the exposure-response relationships. Environ. Health Perspect. 119, 1616-1621. http://dx.doi.org/10.1289/ehp.1103639.

Ramanathan, V., Carmichael, G., 2008. Global and regional climate changes due to black carbon. Nat. Geosci. 1, 221-227.

Rashki, A., Kaskaoutis, D.G., Rautenbach, C.J.deW., Eriksson, P.G., Qiang, M., Gupta, P., 2012. Dust storms and their horizontal dust loading in the Sistan region, Iran. Aeolian Res. 5, 51-62.

Reid, J.S., Hyer, E.J., Johnson, R.S., Holben, B.N., 2013. Observing and understanding the Southeast Asian aerosol system by remote sensing: an initial review and analysis for the Seven Southeast Asian Studies (7SEAS) program. Atmos. Res. 122, 403-468.

Remer, L.A., Kleidman, R.G., Levy, R.C., Kaufman, Y.J., Tanré, D., Mattoo, S., Martins, J.V., Ichoku, C., Koren, I., Yu, H., Holben, B.N., 2008. Global aerosol climatology from the MODIS satellite sensors. J. Geophys. Res. 113, D14S07.

Rohen, G.J., von Hoyningen-Huene, W., Kokhanovsky, A., Dinter, T., Vountas, M., Burrows, J.P., 2010. Retrieval of aerosol mass load ( $\left.\mathrm{PM}_{10}\right)$ from MERIS/Envisattop of atmosphere spectral reflectance measurements. Atmos. Meas. Tech. Discussions 3 , 5429-5467.

Roy, S., 2012. Prediction of particulate matter concentrations using artificial neural network. Resour. Environ. 2 (2), 30-36.

Schaap, M., Apituley, A., Timmermans, R.M.A., Koelemeijer, R.B.A., de Leeuw, G., 2009 Exploring the relation between aerosol optical depth and $\mathrm{PM}_{2.5}$ at Cabauw, The Netherlands. Atmos. Chem. Phys. 9, 909-925. http://dx.doi.org/10.5194/acp-9-9092009.

Seeman, S.W., Borbas, E.E., Li, J., Menzel, W.P., Gumley, L.E., 2006. MODIS atmospheric profile retrieval algorithm theoretical basis document. Version 6, 1-37.

Seo, S., Kim, J., Lee, H., Jeong, U., Kim, W., Holben, B.N., Kim, S.-W., Song, C.H., Lim, J.H., 2015. Estimation of $\mathrm{PM}_{10}$ concentrations over Seoul using multiple empirical models with AERONET and MODIS data collected during the DRAGON-Asia campaign. Atmos. Chem. Phys. 15, 319-334. http://dx.doi.org/10.5194/acp-15-319 2015 .

Sheehan, P.E., Bowman, F.M., 2001. Estimated effects of temperature on secondary organic aerosol concentrations. Environ. Sci. Technol. 135, 2129-2135.

Sinha, P.R., Manchanda, R.K., Kaskaoutis, D.G., Kumar, Y.B., Sreenivasan, S., 2013. Seasonal variation of surface and vertical profile of aerosol properties over a tropical urban station Hyderabad, India. J. Geophys. Res. 118, 749-768. http://dx.doi.org/ 10.1029/2012JD018039.

Sinha, P.R., Gupta, P., Kaskaoutis, D.G., Sahu, L.K., Nagendra, N., Manchanda, R.K., Kumar, Y.B., Sreenivasan, S., 2015. Estimation of particulate matter from satellite and ground based observations over Hyderabad, India. Intern. J. Rem. Sens. 36 (24), 6192-6213.

Snider, G., Weagle, C.L., Murdymootoo, K.K., et al., 2016. Variation in Global Chemical Composition of $\mathrm{PM}_{2.5}$ : Emerging Results from SPARTAN. Atmos. Chem. Phys. 16, 9629-9653. http://dx.doi.org/10.5194/acp-2016-62.

Sotoudeheian, S., Arhami, M., 2014. Estimating ground-level $\mathrm{PM}_{10}$ using satellite remote sensing and ground-based meteorological measurements over Tehran. J. Environ. Health Sci. Eng. 2014 (12), 122. http://www.ijehse.com/content/12/1/122.

Takekawa, H., Minoura, H., Yamazaki, S., 2003. Temperature dependence of secondary organic aerosol formation by photo-oxidation of hydrocarbons. Atmos. Environ. 37, 3413-3424.

Titos, G., Lyamani, H., Cazorla, A., Sorribas, M., Foyo-Moreno, I., Wiedensohler, A., Alados-Arboledas, L., 2014. Study of the relative humidity dependence of aerosol 
light-scattering in southern Spain. Tellus B 66, 24536. http://dx.doi.org/10.3402/ tellusb.v66.24536.

Valenzuela, A., Olmo, F.J., Lyamani, H., Antón, M., Titos, G., Cazorla, A., AladosArboledas, L., 2015. Aerosol scattering and absorption Angström exponents as indicators of dust and dust-free days over Granada (Spain). Atmos. Res. 154, 1-13.

Van Donkelaar., A., Martin, R.V., Brauer, M., Kahn., R., Levy., R., Verduzco., C., Villeneuve, 2010. Global estimates of ambient fine particulate matter concentrations from satellite-based aerosol optical depth: development and application. Environ. Health Perspect. 118 (6), 847-855. http://dx.doi.org/10.1289/ehp.0901623.

Voogt, J.A., Oke, T.R., 2003. Thermal remote sensing of urban climates. Remote Sens. Environ., vol. 86 (Issue 3), 370-384 (ISSN 0034-4257).

Wang, J., Christopher, S.A., 2003. Intercomparison between satellite-derived aerosol optical thickness and $\mathrm{PM}_{2.5}$ mass: implications for air quality studies. Geophys. Res. Lett. 30, 2095. http://dx.doi.org/10.1029/2003GL018174.

Wang, J., Martin, S.T., 2007. Satellite characterization of urban aerosols: Importance of including hygroscopicity and mixing state in the retrieval algorithms. J. Geophys. Res. 112 (D17203), 1-18. http://dx.doi.org/10.1029/2006JD008078.

Wang, J., Ge, C., Yang, Z., Hyer, E.J., Reid, J.S., Chew, B.-N., Mahmud, M., Zhang, Y., Zhang, M., 2013. Mesoscale modeling of smoke transport over the Southeast Asian Maritime Continent: interplay of sea breeze, trade wind, typhoon, and topography.
Atmos. Res. 122, 486-503.

Willmott, C.J., 1981. On the validation of models. Phys. Geogr. 2, 184-194.

Willmott, C.J., Robeson, S.M., Matsuura, K., 2012. A refined index of model performance. Int. J. Climatol. 32, 2088-2094.

Xiao, Z., 2011. Estimation of the main factors influencing haze, based on a long-term monitoring campaign in Hangzhou, China. Aerosol Air Qual. Res. 11, 873-882.

Xiao, F., Wong, M.S., Lee, K.H., Campbell, J.R., She, Y.-k., 2015. Retrieval of Dust Storm Aerosols Using an Integrated Neural Network Model. Computers \& Geosciences, in press http://dx.doi.org/10.1016/j.cageo.2015.02.016.

Xie, Y., Wang, Y., Zhang, K., Dong, W., Lv, B., Bai, Y., 2015. Daily estimation of groundlevel $\mathrm{PM}_{2.5}$ concentrations over Beijing using $3 \mathrm{~km}$ resolution MODIS AOD. Environ. Sci. Technol. 49 (20), 12280-12288.

Yao, L., Lu, N., Jiang, S., 2012. Artificial neural network (ANN) for multi-source $\mathrm{PM}_{2.5}$ estimation using surface, MODIS, and meteorological data. In: Biomedical Engineering and Biotechnology (iCBEB), 2012 International Conference on, vol., no., pp.1228, pp. 1231. http://dx.doi.org/10.1109/iCBEB.2012.81.

Yap, X.Q., Hashim, M., 2013. A robust calibration approach for $\mathrm{PM}_{10}$ prediction from MODIS aerosol optical depth. Atmos. Chem. Phys. 13, 3517-3526 (2013).

Zhang, J., Reid, J.S., Holben, B.N., 2005. An analysis of potential cloud artifacts in MODIS over ocean aerosol optical thickness products. Geophys. Res. Lett. 32, L15803. 